ORNL/TM-2021/2068

\title{
Assessment of Commercial Composite Power Pole Performance
}

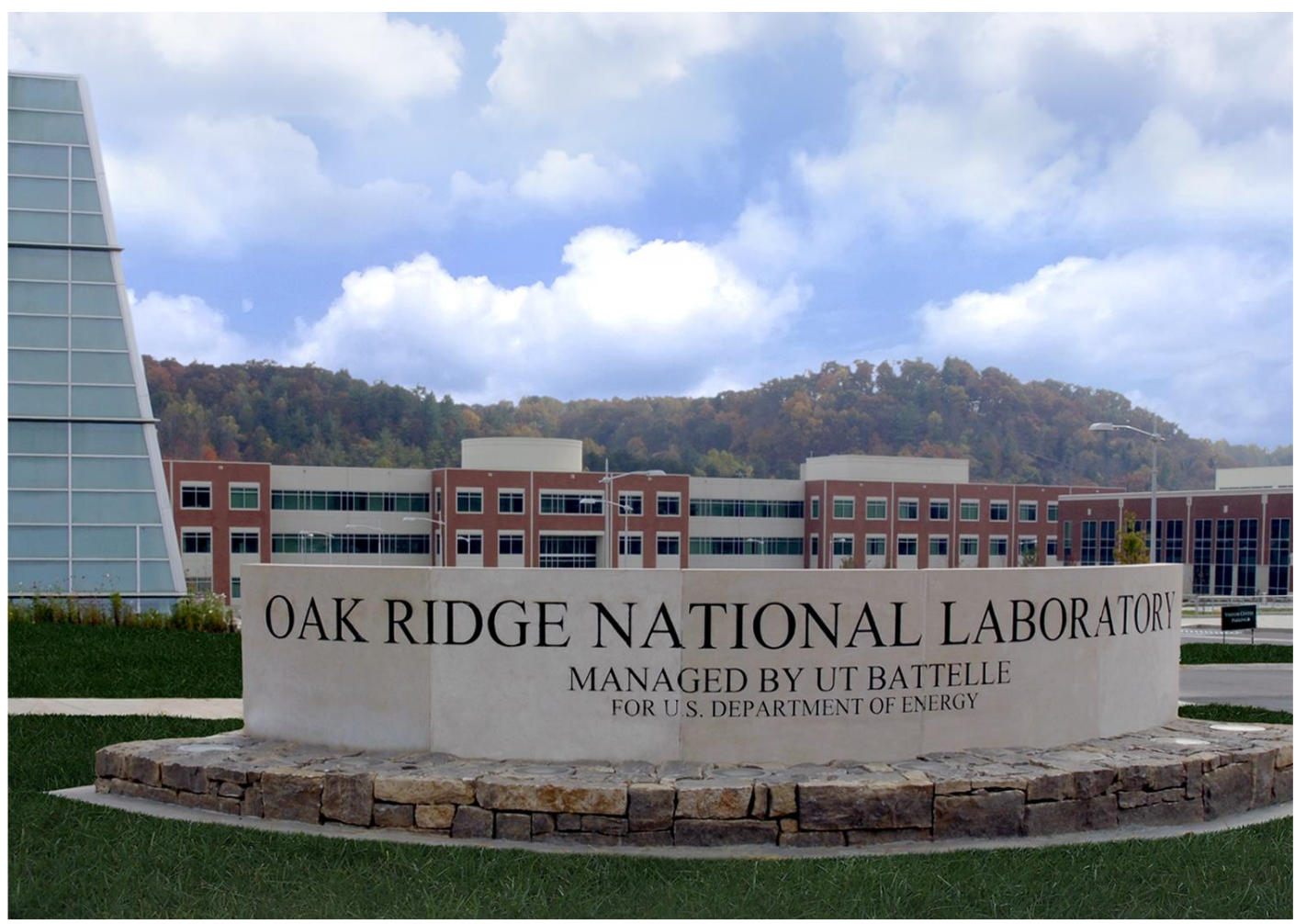

Lonnie Love

Brian Post

Halil Tekinalp

Peter Wang

Celest Atkins

Alex Roschli

Xianhui (Andy) Zhao

Mitch Rencheck

May 2021 


\section{DOCUMENT AVAILABILITY}

Reports produced after January 1, 1996, are generally available free via US Department of Energy (DOE) SciTech Connect.

Website http://www.osti.gov/scitech/

Reports produced before January 1, 1996, may be purchased by members of the public from the following source:

National Technical Information Service
5285 Port Royal Road
Springfield, VA 22161
Telephone 703-605-6000 (1-800-553-6847)
TDD 703-487-4639
Fax 703-605-6900
E-mail info@ntis.gov
Website http://www.ntis.gov/help/ordermethods.aspx

Reports are available to DOE employees, DOE contractors, Energy Technology Data Exchange representatives, and International Nuclear Information System representatives from the following source:

Office of Scientific and Technical Information

PO Box 62

Oak Ridge, TN 37831

Telephone 865-576-8401

Fax 865-576-5728

E-mail reports@osti.gov

Website http://www.osti.gov/contact.html

This report was prepared as an account of work sponsored by an agency of the United States Government. Neither the United States Government nor any agency thereof, nor any of their employees, makes any warranty, express or implied, or assumes any legal liability or responsibility for the accuracy, completeness, or usefulness of any information, apparatus, product, or process disclosed, or represents that its use would not infringe privately owned rights. Reference herein to any specific commercial product, process, or service by trade name, trademark, manufacturer, or otherwise, does not necessarily constitute or imply its endorsement, recommendation, or favoring by the United States Government or any agency thereof. The views and opinions of authors expressed herein do not necessarily state or reflect those of the United States Government or any agency thereof. 
Manufacturing Science Division

Oak Ridge National Laboratory

\title{
Assessment of Commercial Composite Power Pole Performance
}

\author{
Authors \\ Lonnie Love \\ Brian Post \\ Halil Tekinalp \\ Alex Roschli \\ Peter Wang \\ Celeste Atkins \\ Xianhui (Andy) Zhao \\ Mitch Rencheck
}

Date Published:

May, 2021

\author{
Prepared by \\ OAK RIDGE NATIONAL LABORATORY \\ Oak Ridge, Tennessee 37831-6283 \\ managed by \\ UT-BATTELLE, LLC \\ for the \\ US DEPARTMENT OF ENERGY \\ under contract DE-AC05-00OR22725
}





\section{CONTENTS}

CONTENTS

LIST OF FIGURES .

List of Table vii

ACKNOWLEDGEMENTS ix

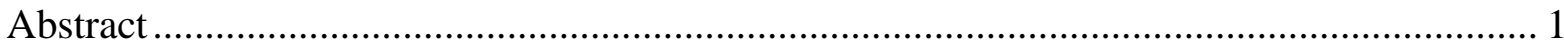

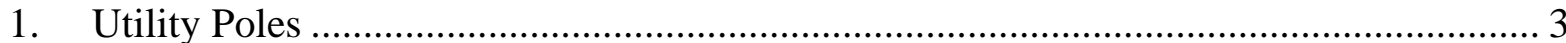

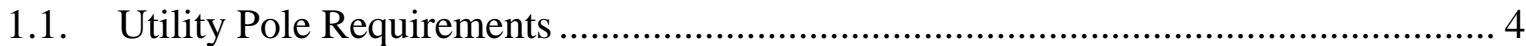

1.2. Overview of Wooden Utility Poles .................................................................. 7

1.3. OVerview of Steel Utility poles ....................................................................... 9

1.4. Overview of Concrete Utility Poles .............................................................. 10

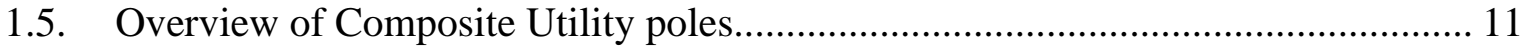

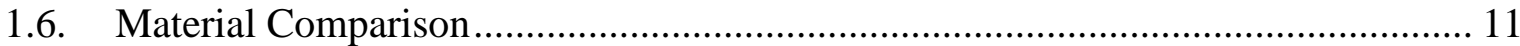

1.7. Utility Poles In Severe Weather Events ......................................................... 12

2. Overview of Composite Power Pole Production ....................................................... 15

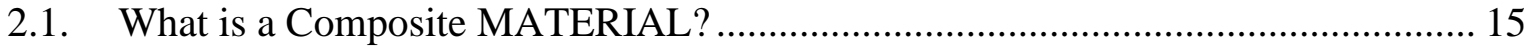

2.2. How Are Composite Poles Manufactured? ...................................................... 16

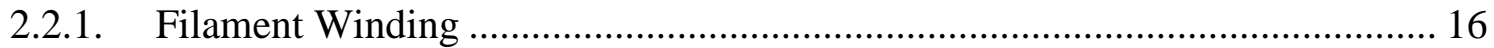

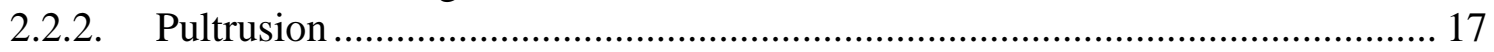

2.3. History of Composite Utility Poles .................................................................. 18

3. Overveiw of Current Composite Power Pole Performance ......................................... 19

4. Assessment of Knowledge Gaps and Future Opportunities .................................. 23

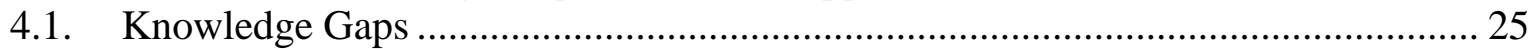

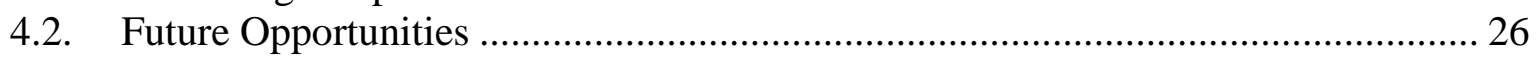

4.2.1. REcycled BioMaterials for Short Term Disaster Relief ................................. 26

4.2.2. Use of Waste Streams for Low-Cost Composite Poles ..................................... 26

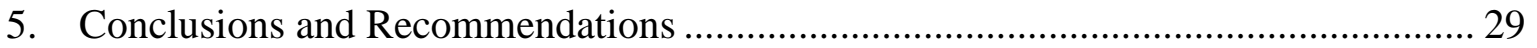

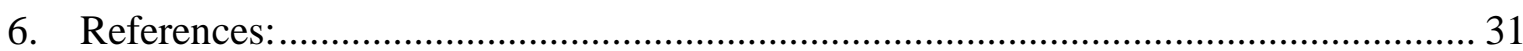




\section{LIST OF FIGURES}

Figure 1: First drawing of telegraph pole, June 25, 1844 ............................................. 3

Figure 2: Marker commemorating first electrical communication ................................... 3

Figure 3: Utility pole in 1900's ............................................................................. 4

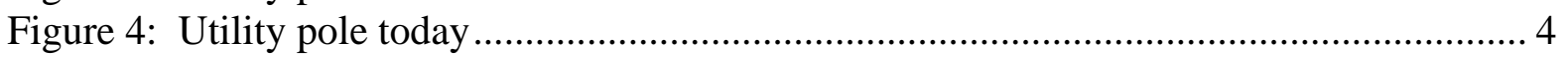

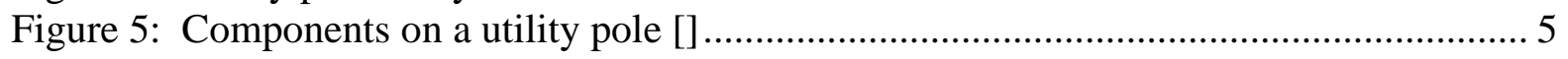

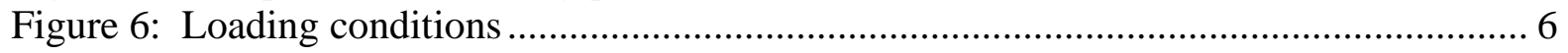

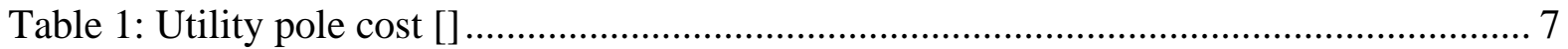

Table 2: Comparison of two common wood poles …................................................... 8

Figure 7. The power pole damaged by fire at the transformer mounting bolt.[] ................... 9

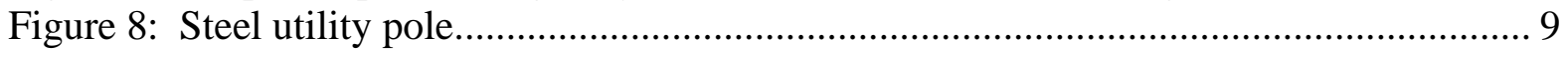

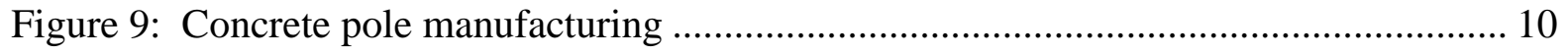

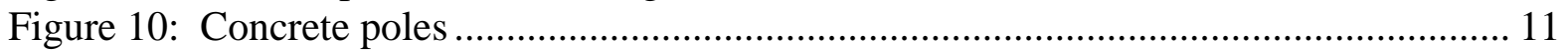

Figure 11: Survival curves for pole materials [ .......................................................... 12

Figure 12: Pole damage from Hurricane Harvey ........................................................ 13

Figure 13: Pole damage from Hurricane Maria ........................................................... 13

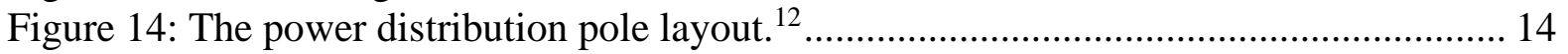

Table 3: The comparison of penta-treated wood, concrete, and steel poles ......................... 14

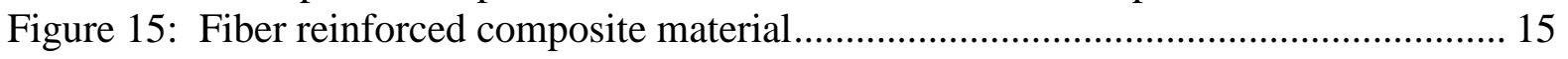

Figure 16: Material usage in Boeing 787 ...................................................................... 15

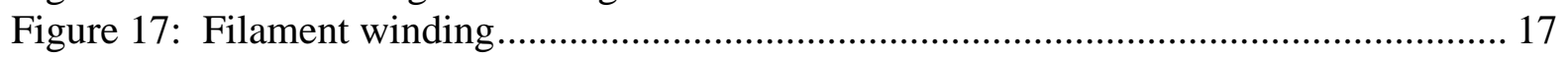

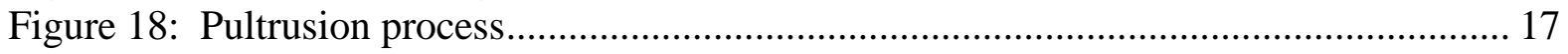

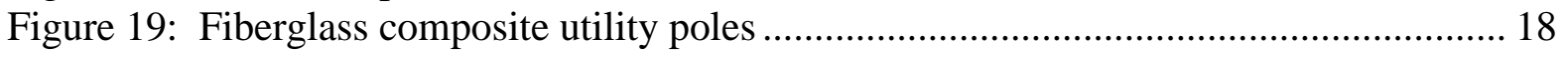

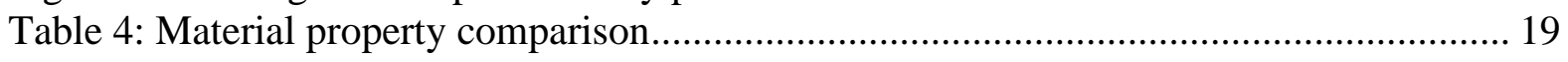

Table 5: The laminate flexural strength retention of composite utility poles made by RS

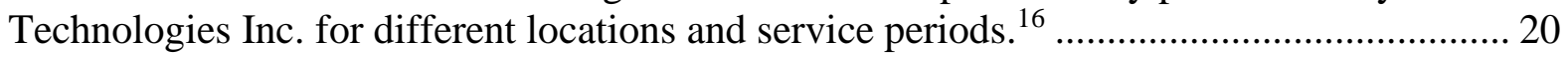

Figure 20: A new composite pole was set in this distribution line. Due to its lightness, the composite pole is easier to install than the wooden or other heavier poles.[25] .................. 21

Figure 21: Vibration testing machine.[26] ................................................................ 24

Figure 22: Pole crossarm with zero perch deflector spike (left), two perch deflector spikes (center), and four perch deflector spikes (right). Experimental results show that the perch deflectors can reduce the electrocution frequency on line poles.[29]................................... 25

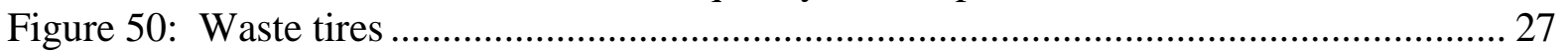

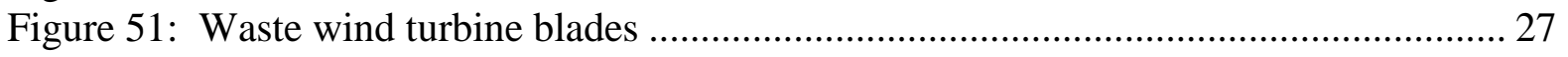




\section{LIST OF TABLES}

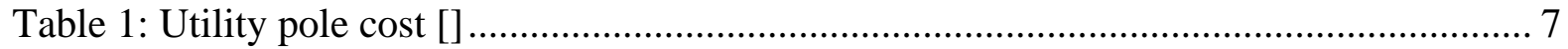

Table 2: Comparison of two common wood poles .......................................................... 8

Table 3: The comparison of penta-treated wood, concrete, and steel poles ......................... 14

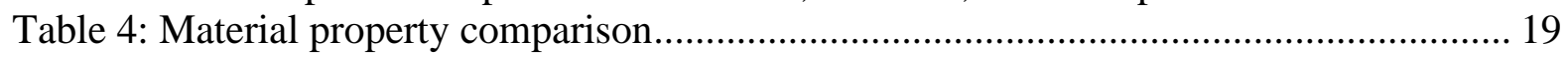

Table 5: The laminate flexural strength retention of composite utility poles made by RS

Technologies Inc. for different locations and service periods. ${ }^{16}$ 20 


\section{ACKNOWLEDGEMENTS}

This effort was conducted as an Office of Electricity project within the Oak Ridge National Laboratory (ORNL) Manufacturing Demonstration Facility (MDF) sponsored by the US Department of Energy Advanced Manufacturing Office (CPS Agreement Number 24761). The goal of the effort was to engage industry partners to participate in short-term, collaborative projects within the Manufacturing Demonstration Facility (MDF) to assess applicability and of new energy efficient manufacturing technologies. Research was sponsored by the U.S. Department of Energy, Office of Energy Efficiency and Renewable Energy, Office of Electricity, under contract DE-AC0500OR22725 with UT-Battelle, LLC. 


\begin{abstract}
The objective of this report is to assess the performance of composite poles, considering price, durability, resilience to the effects of extreme weather, ongoing maintenance costs, ease of repair, preplacement or upgrading giving special consideration to performance in watersheds and flood prone environments. The report starts with a description of the history and functional requirements of power pole. This is followed by a survey of existing composite pole manufacturing processes with a survey of existing knowledge base answering the above performance requirements. For the information not currently available to the public, an overview of testing procedures is outlined. Finally, an overview of emerging trends in composites and potential opportunities to address technical and economic shortfalls is proposed.
\end{abstract}




\section{UTILITY POLES}

In 1843, the United States Congress gave Samuel Morse $\$ 30,000$ for a demonstration project to prove a message could be sent over a distance more efficiently and quickly than current means such as flags or lights. Morse and his partners began laying transmission lines under ground between the capital building in Washington DC and a railroad station 38 miles away in Baltimore. Unfortunately, the wires were defective and finding the issues was problematic with buried lines. One of Morse's partners suggested the quickest way to complete the project would be to string the telegraph wires overhead on trees with wooden poles (see Figure 1 and Figure 2). Soon after this successful demonstration, telegraph poles started being erected across the country enabling the beginning of the first form of electrical communication.

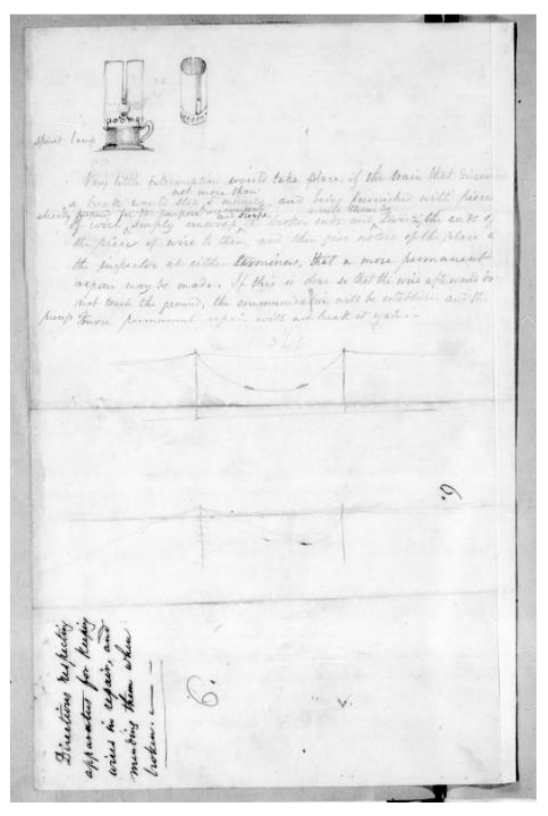

Figure 1: First drawing of telegraph pole, June 25, 1844

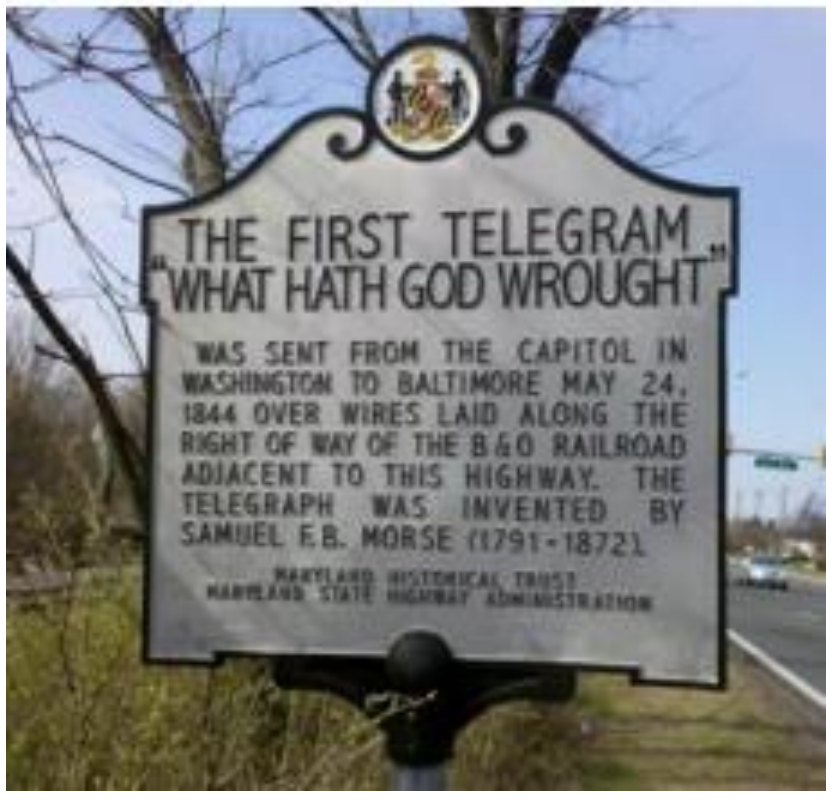

Figure 2: Marker commemorating first electrical communication

Over the past 150 years, the telegraph pole has transformed into the utility pole carrying telephone lines, electrical lines and, more recently, video services, internet, fiber optics as well as streetlights. The transition from DC to AC in the early $20^{\text {th }}$ Century added the complexity of high voltage, insulators, and transformers. While the role, and demands, of the utility pole have increased, the basic pole itself has remained relatively unchanged (see Figure 3 and Figure 4). 


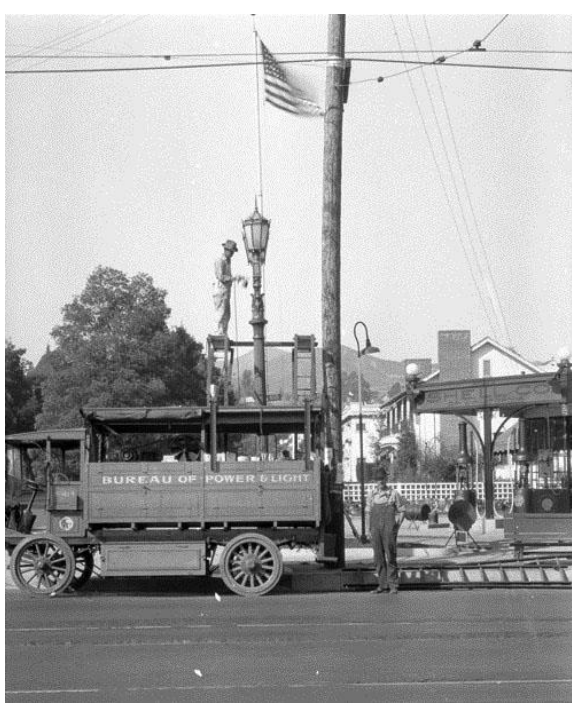

Figure 3: Utility pole in 1900's

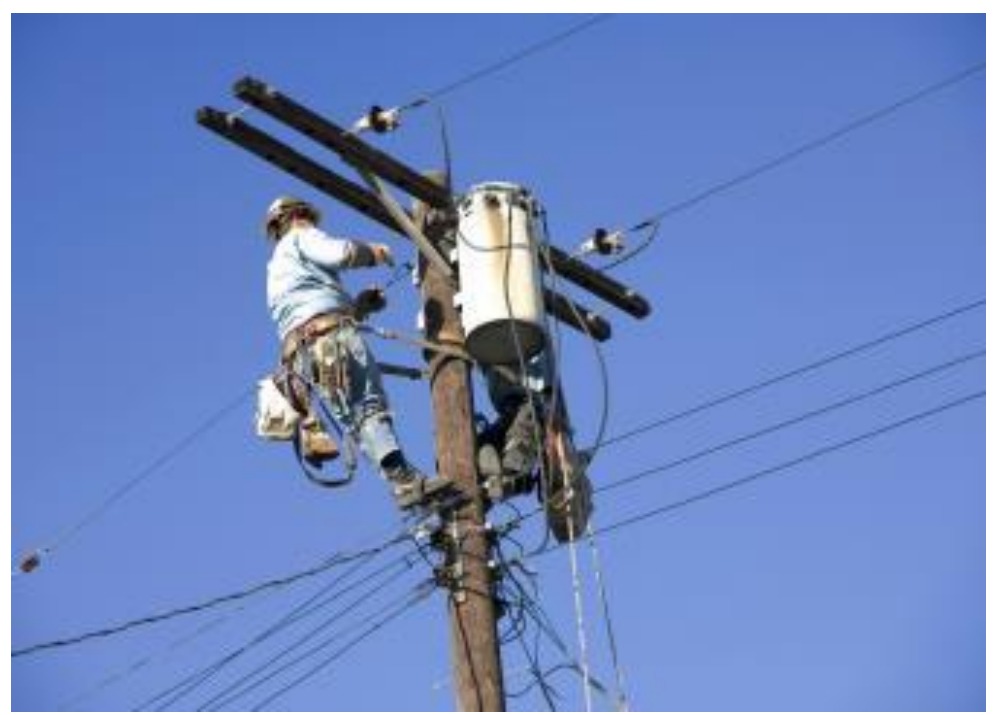

Figure 4: Utility pole today

\subsection{UTILITY POLE REQUIREMENTS}

A utility pole is a column or post used to support overhead power lines and other various public utilities such as fiber optic cables, electrical cables and related equipment such as transformers and streetlights. There are an estimated 180 million utility poles in the US that come in a variety of different sizes, shapes and materials. The standard utility pole in the US is approximately $40 \mathrm{ft}$ long and is buried $6 \mathrm{ft}$ in the ground. However, poles can reach to heights of $120 \mathrm{ft}$ or more based on clearance requirements. They are typically spaced $125 \mathrm{ft}$ apart in urban areas and $300 \mathrm{ft}$ apart in rural areas, but distance can vary widely due to terrain. 


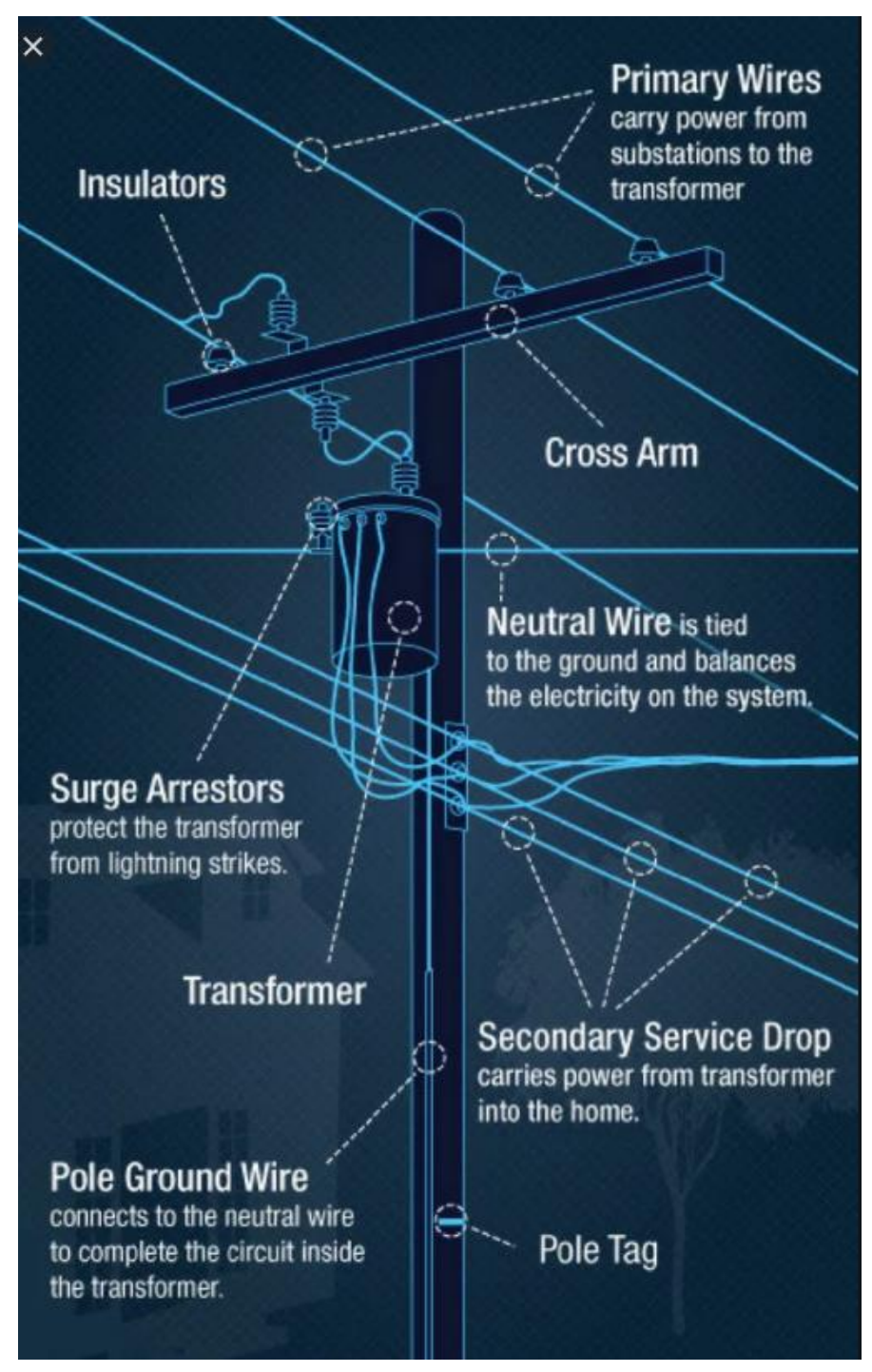

Figure 5: Components on a utility pole [1]

As will be discussed, there are a wide variety of materials and designs for distribution and transmission poles including wood, steel, concrete, fiberglass and other emerging structural materials. Prevailing U.S. practice and most state laws require basic safety requirements from the National Electrical Safety code (NESC) that defines basic standards for dimensions and loads. NESC specifies strength and loading rules based on the construction grade of the line and environmental loading district (wind and/or ice) to meet basic safety requirements. Because of these NESC-specified safety requirements, it is necessary to perform a Pole Loading Analysis (PLA) for the design of new pole installation as well as existing poles when the facilities on the pole will be changed. NESC specifies strength and loading rules based on three different grades of construction that determines the different margins of safety. Higher grades of construction translate to higher levels of structural reliability and safety to withstand the environmental conditions of ice and/or wind loads. Grade B provides the highest margin of safety and is required when the pole supports span highways, railroads and waterways. Grade $\boldsymbol{C}$ is most common and provides basic margin of safety and is often utilized for typical 
power pole and joint-use distribution poles. Grade $N$ is the lowest grade of construction and is most often used for emergency or temporary construction.

NESC specifies two different environmental loading conditions (wind and ice-winter storm) with the poles must withstand. The conditions are divided into three loading zones on the mainland United States plus warm island loading zones used in locations such as Hawaii, Puerto Rico and the Virgin Islands. The heavy loading zone incorporates $1 / 2$ inch of radial ice buildup and 4 pounds pr square foot wind pressure. The medium loading zone incorporates $1 / 4$ inch radial ice buildup and 4 pounds per square foot wind pressure. The light loading zone corresponds to 9 pounds per square foot of wind pressure without adding ice to wire diameters.

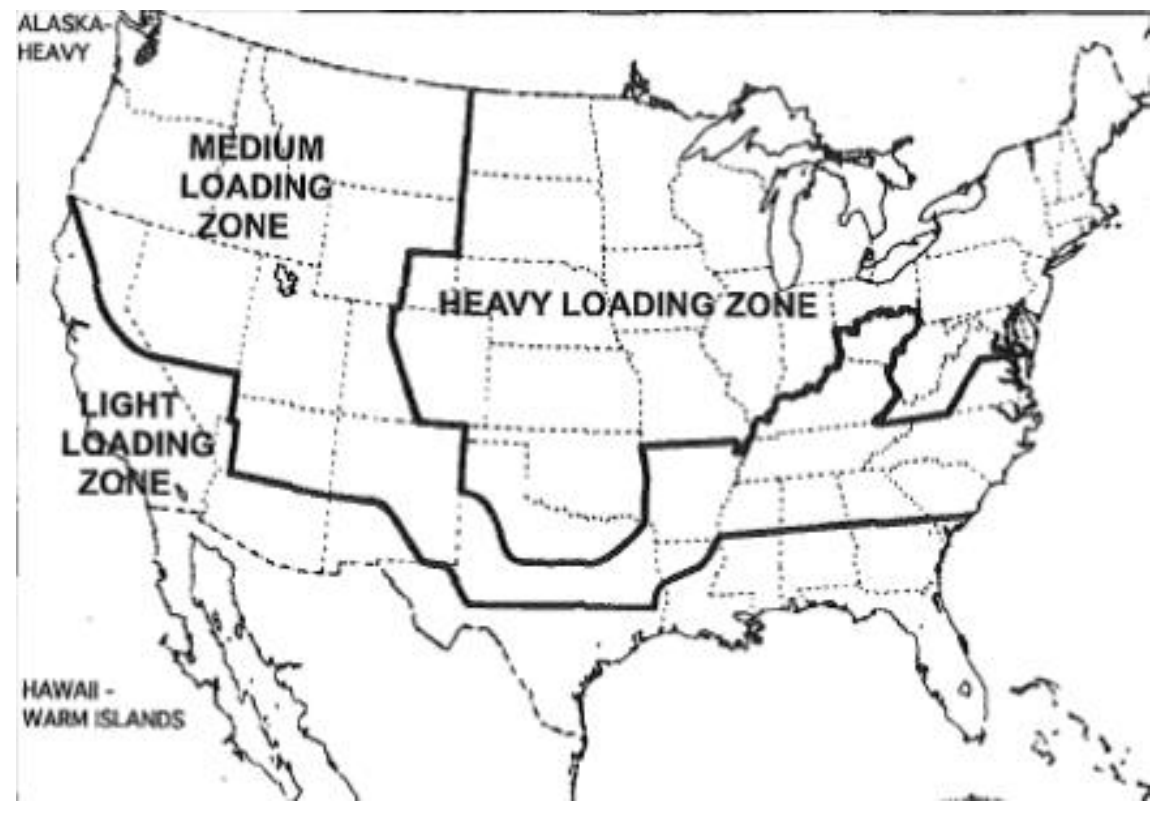

Figure 6: Loading conditions

Ultimately it is the strength of the pole that determines if the pole in use with the various electrical and telecommunications equipment and spans attached can withstand environmental loading for the necessary level of reliability. Utility poles, wood poles in particular, are classified by their size and strength into six pole classes (Class 4, Class 3, Class 2, Class 1, Class H1, Class H2). As you move down the class number, the diameter and strength of the pole increases. The bending strength of the pole determines the load bearing capacity. The design process corresponds to picking the class of pole based on the required grade of construction, loading district and the equipment/spans that the pole must carry. The loading district, spans and equipment mounted on the pole define the lateral loads. The most significant parameters of the pans that effect loading include the attachment height, diameter, span length and span angles. In addition, as poles age, the strength of the pole may decrease due to damage or decay. Most poles have safety factors between 2 and 4 depending upon construction grade.[2]

The above requirements (loads and safety factors) coupled with the material selection and geometric requirements drive the final pole design. The following sections outline material 
options for utility pole manufacturing. The most common material is timber, but environmental conditions have led to additional options including steel, concrete and composites.

\subsection{OVERVIEW OF WOODEN UTILITY POLES}

Most poles are manufactured from wood, pressure-treated with some form of preservative for protection against rot and insects. The poles must be long and straight. Typical species of trees include southern yellow pine, Douglas fir, jack pine, western red cedar and Pacific silver fir. There are a wide variety of requirements for a tree to qualify as a utility pole. Issues such as knots, scars, swelling, moisture contact, handling (contact with the ground from the time they are cut), grain and crooks can prevent a tree from qualifying as a utility pole. In addition to geometric requirements (height, diameter), the pole must pass mechanical requirements such as ultimate loads, deflections, and weights. The traditional preservative used in utility poles was creosote, but due to environmental concerns, this preservative is being phased out and replaced with alternatives such as pentachlorophenol, copper naphthenate and borates. Once harvested, treatment for the poles to dry and impregnate with preservatives can take up to two years. Even with preservatives, the standard life of a wood pole is 25 to 50 years depending upon climate. Natural wood decomposes and cannot be used in the construction of utility structures without the aid of a chemical preservative. Most of these preservatives are harmful to the environment. When the wood pole falls into disrepair and is discarded in a landfill, the chemicals will seep into the ground. Prices for utility poles vary depending upon size, material, and geographic location. The standard cost for a $40 \mathrm{ft}$ wooden utility pole is typically under $\$ 1000$ (see Table 1).

Table 1: Utility pole cost [3]

\begin{tabular}{|c|c|}
\hline Pole Size & Price Range \\
\hline 25 -foot & $\$ 100$ to $\$ 200$ \\
\hline 30 -foot & $\$ 100$ to $\$ 350$ \\
\hline 35 -foot & $\$ 250$ to $\$ 425$ \\
\hline 40 -foot & $\$ 350$ to $\$ 550$ \\
\hline 45 -foot & $\$ 400$ to $\$ 700$ \\
\hline 50 -foot & $\$ 500$ to $\$ 850$ \\
\hline 55 -foot & $\$ 650$ to $\$ 850$ \\
\hline
\end{tabular}

O'Toole and Tong conducted a comparison between two common wood poles. The wood dimensions and properties are based on a $40 \mathrm{ft}$ Class 1 Douglas Fir and Western Red Cedar pole data (see table 2). A Class 1 wood pole is considered a high-quality structure. 
Table 2: Comparison of two common wood poles

\begin{tabular}{|l|c|c|c|c|c|}
\hline Pole & $\begin{array}{c}\text { Diameter } \\
\text { (in) }\end{array}$ & $\begin{array}{c}\text { Weight } \\
(\text { lbs })\end{array}$ & $\begin{array}{c}\text { Stiffness } \\
\text { (psi x 106) }\end{array}$ & $\begin{array}{c}\text { Strength } \\
\text { (psi) }\end{array}$ & $\begin{array}{c}\text { Max Moment } \\
\text { (ft-kip) }\end{array}$ \\
\hline Douglas Fir & 13.37 & 1760 & 1.9 & 7700 & 150.6 \\
\hline Red Cedar & 14.64 & 1320 & 1.5 & 5600 & 143.9 \\
\hline
\end{tabular}

The natural environment has an impact on the wooden utility poles' performance. For example, termite can damage the wood power poles. It was estimated that the termite damage to wood power poles costs approximately $\$ 20$ million annually in Australia.[4] In addition, wooden utility pole fire (shown in Figure 7) caused by leakage current flow has become a major issue for various power distribution utilities.[5] 


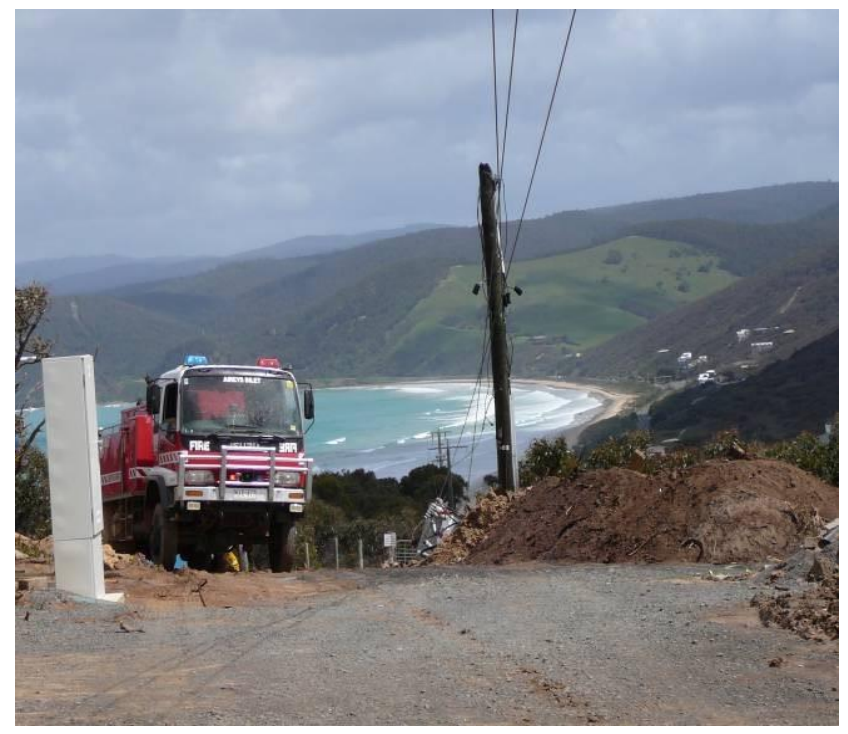

Figure 7. The power pole damaged by fire at the transformer mounting bolt.[5]

\subsection{OVERVIEW OF STEEL UTILITY POLES}

Galvanized steel poles are similar to concrete poles in terms of advantages (strong, rot and fire resistant). Of all the options, steel power poles have one unique characteristic that they are $100 \%$ recyclable. They are self-conducting for grounding purposes, therefore not requiring full length copper grounding wires. They weigh approximately $50 \%$ to $70 \%$ less than comparable wood structures. Since they are engineered structures, rather than natural materials, there is great repeatability in geometric precision and mechanical properties. The main disadvantages are higher costs, difficult to fix and prone to corrosion. Since 1998, close to one million steel distribution poles have been installed and are now being used by over 600 of the 3100 U.S. electric utilities (see Figure 8).[6]

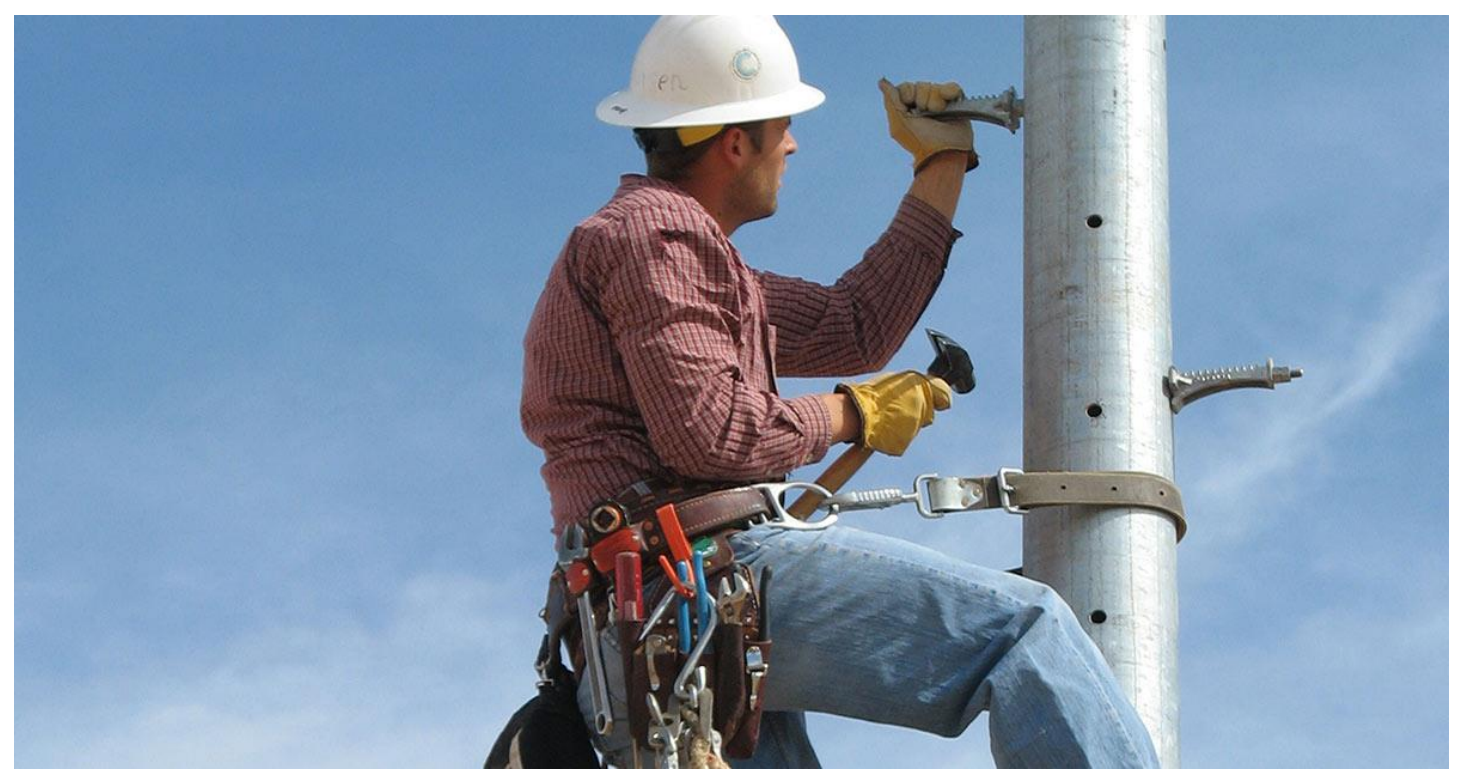

Figure 8: Steel utility pole 


\subsection{OVERVIEW OF CONCRETE UTILITY POLES}

Concrete utility poles are strong, uniform in appearance, and resistant to rot, termite, fire and ice. Their primary disadvantages are that they can be difficult to repair, very heavy, higher cost than wooden poles, steel reinforcement corrodes resulting in failure, uses large quantities and energy and are environmentally unfriendly due to the large $\mathrm{CO}_{2}$ emissions from the concrete industry. Poles are manufactured with prestressed galvanized wire and reinforcement bars. During manufacturing, the pole undergoes centrifugal spinning process that results in a high density, yet hollow, pole thereby reducing the weight and providing a smooth conduit for electrical and communication cables (see Figure 9 and Figure 10).[7]
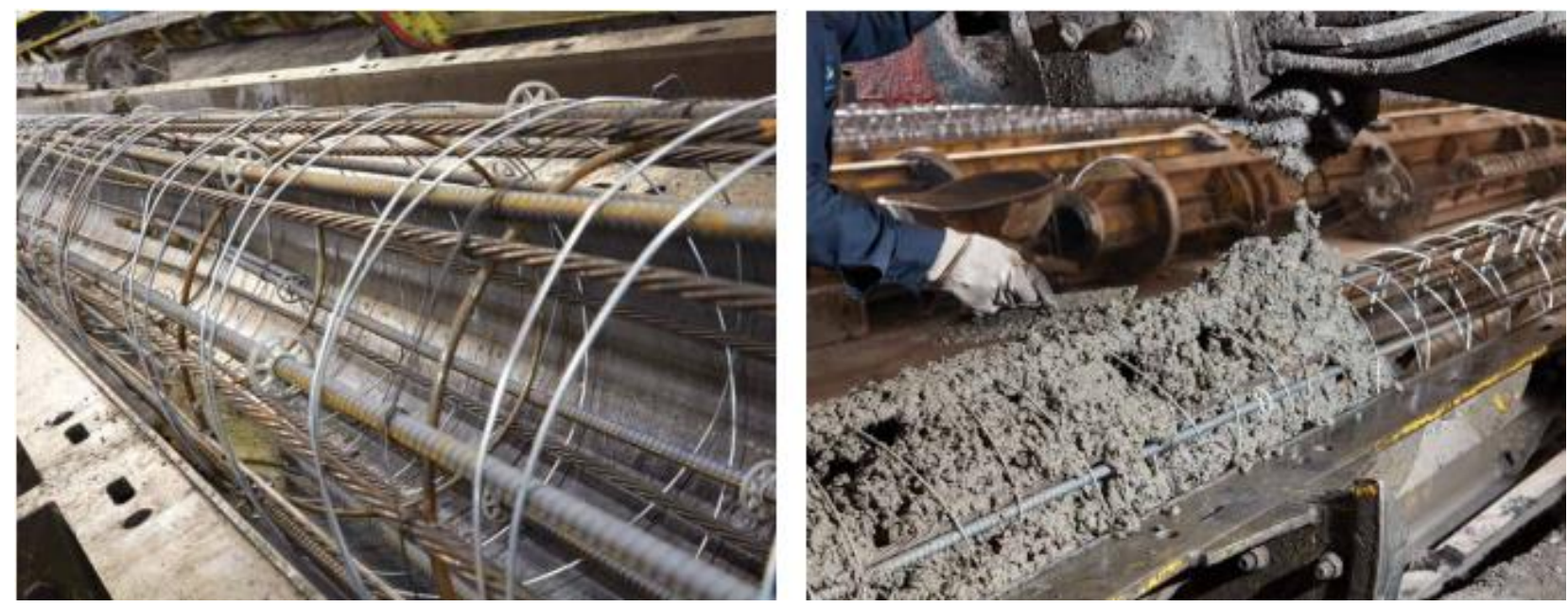

Figure 9: Concrete pole manufacturing 


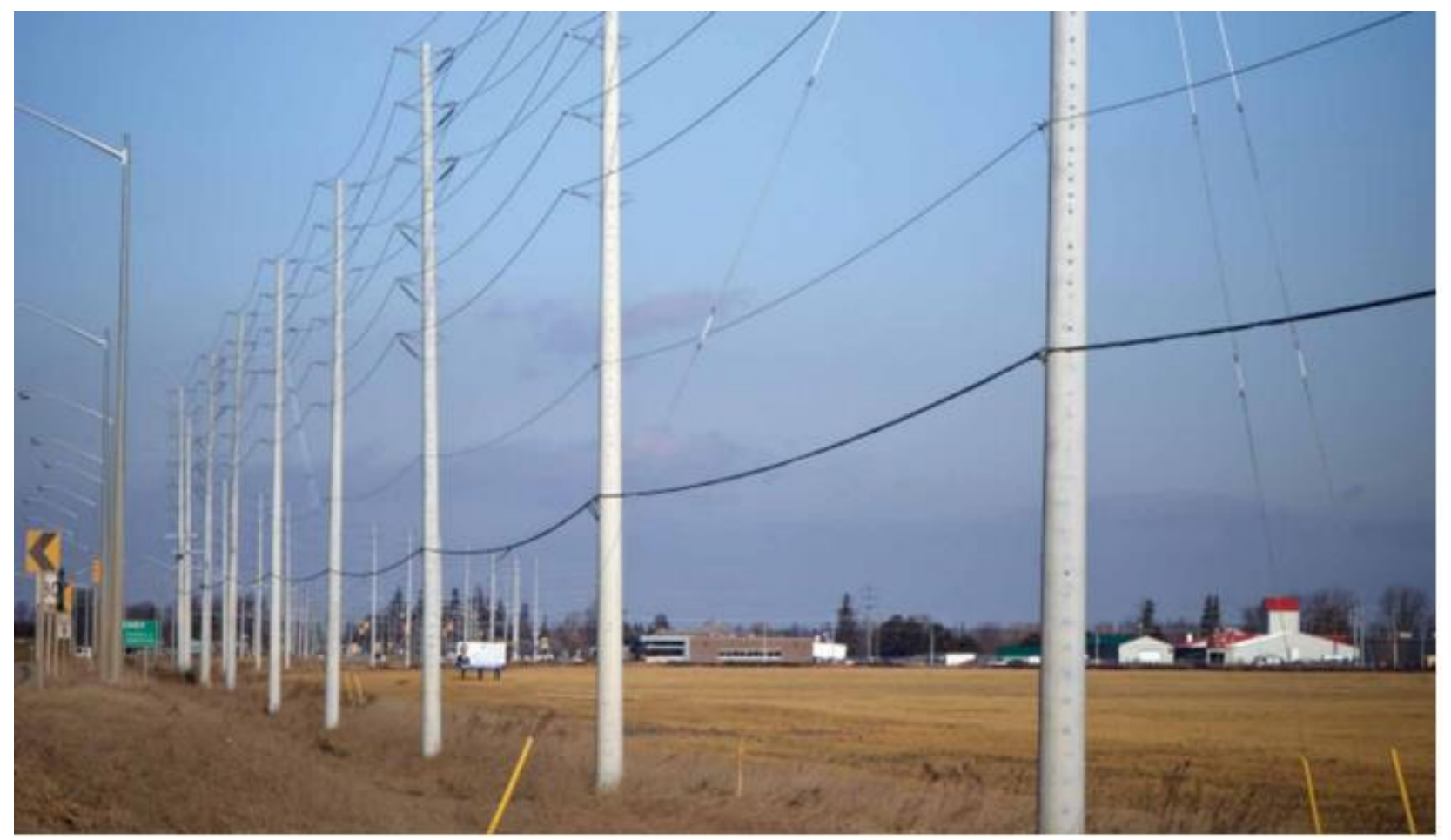

Figure 10: Concrete poles

\subsection{OVERVIEW OF COMPOSITE UTILITY POLES}

Composite utility poles currently make up about $1 \%$ of the total deployed utility poles globally. Composite, fiber-reinforced polymer (FRP), or fiberglass utility poles were first installed in Hawaii in the early 1960's due to the high humidity, high wind environment. These poles lasted approximately 50 years and were replaced due to degradation from ultraviolet light exposure. With modern UV inhibitors, the anticipated life of the composite poles is projected to be over 80 years. As experienced in Hawaii, the main advantages are the corrosion resistance of the material, low maintenance requirements, immunity to termites and pest infestation. Structurally, composites have very high stiffness and strength. The primary disadvantages are poor fire resistance, higher cost and unproven long-term use.[8]

\subsection{MATERIAL COMPARISON}

There have been limited comparative studies on utility pole materials (see Figure 11). Lifetime cost is the key to deciding which technology is ideal for a given circumstance. While wooden poles are the least expensive upfront, as described earlier, concerns over preservatives, durability and failure modes (and subsequent costs) in harsh environments such as hurricanes and wildfires need to be considered. On the other hand, for concrete poles, the typical failure mode is corrosion on the reinforcing bars. There is currently research focusing on replacing steel reinforcement with fiber reinforcement to extend the lifetime of concrete structures. Steel and wood poles have corrosion and decay (respectively) at the ground line interface. 


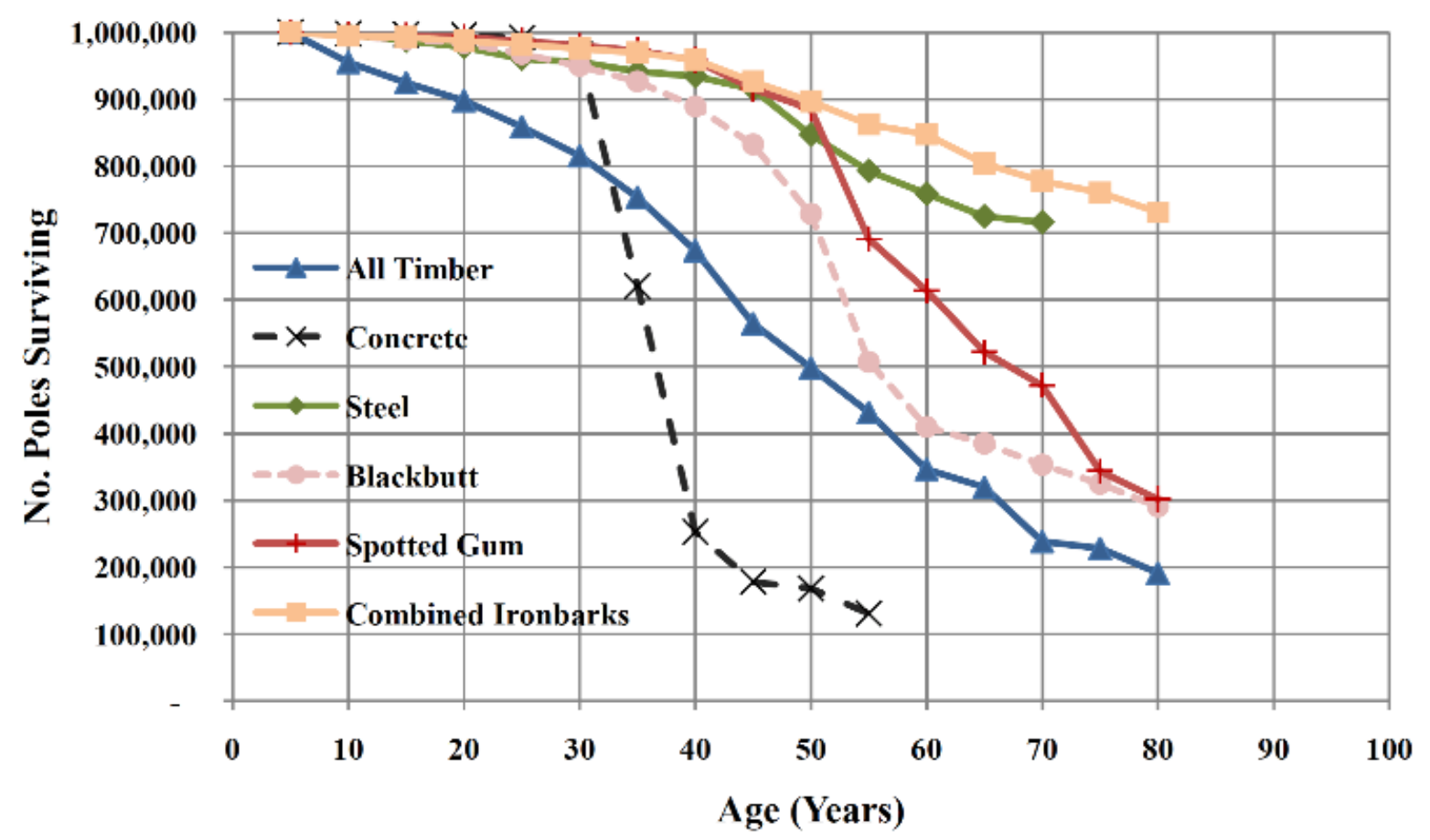

Figure 11: Survival curves for pole materials[9]

\subsection{UTILITY POLES IN SEVERE WEATHER EVENTS}

Inclement weather conditions such as hurricanes, tornadoes and windstorms make a compelling case to replace existing wooden poles with more engineered materials. Utility poles manufactured with composite materials can be made resistant to water damage, heat, impact, insects, and corrosion of any kind. As described earlier, the majority of utility poles are manufactured from a wood product which are vulnerable to severe weather events. There is a need to add chemical coatings to the exterior. This extends the lifespan of the poles and reduces maintenance expenses. An average of 2.5 million of the roughly 130 million wooden utility poles need to be replaced each year due to loss from rot, age, decay, and severe weather events.

When it comes to storm zones, which endure an estimated $\$ 54 \mathrm{~B}$ in damages annually, the economic impact of downed poles is far greater than the cost of infrastructure replacement.[10] Wide-scale grid failures impede the movement of manufactured goods leading to residual losses of critical food and pharmaceuticals. These outages immediately halt economic activity through loss of mass transit, traffic lights, power, and ventilation as well as cold storage. In August 2017, Hurricane Harvey brought down 5,000 wooden utility poles leaving over 250,000 people without power for days. Damage was estimated at \$125B.[11] In September of 2017, Hurricane Maria brought down $80 \%$ of Puerto Rico's wooden poles causing backouts that lasted for weeks (see Figure 12 and Figure 13).[12] 


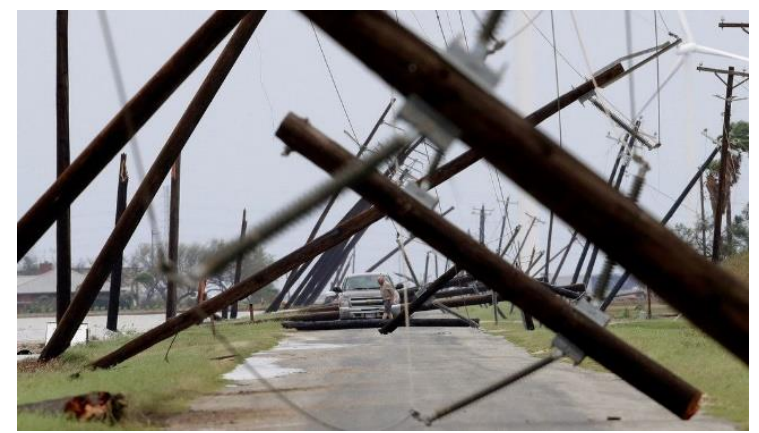

Figure 12: Pole damage from Hurricane Harvey

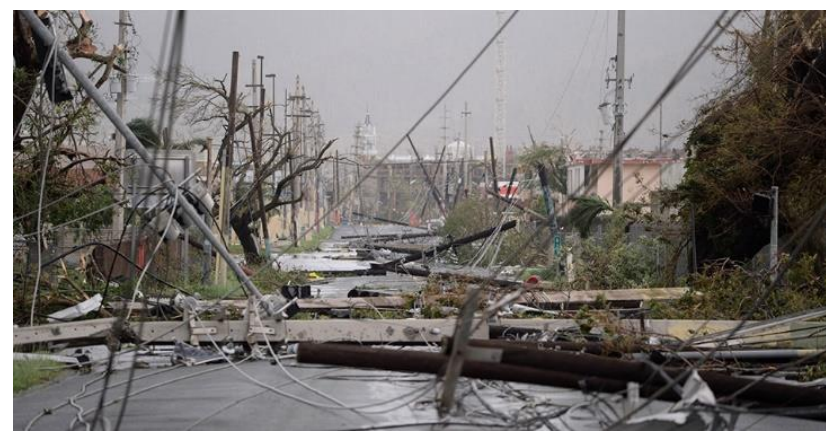

Figure 13: Pole damage from Hurricane Maria

In 2017, a massive windstorm in Rochester New York resulted in severe damage to traditional wooden poles leaving 170,000 residents without power.[13] The New York State Public Service Commission and local utility service providers replaced the damaged wooden poles with composite poles. The replacement cost was approximately $\$ 1.25 \mathrm{M}$ and were estimated less than the maintenance cost of wooden poles.[14] From 2011 to 2015, a series of hurricanes in the Grand Bahamas downed close to 2,700 wooden power poles. None of the 450 composite poles that were installed had been damaged.[15] Likewise, when Hurricane Odile hit the Baja Peninsula of Mexico, a post event evaluation found that most of the wooden poles had sustained damage whereas all the composite poles were still operational.

The Comision Federal de Electricidad (CFO) - Mexico's national utility, decided to replace every fifth pole on their grid with a composite pole in the Baja Peninsula in October 2012 to harden their distribution lines.[16] When Hurricane Odile and it's 125 mile per hour winds struck in September of 2014, these fortified lines were the only ones left standing on the entire peninsula.[17] Similarly, the 450 composite poles installed in the Grand Bahama in 2009 have withstood major hurricanes including Irene and Matthew which took down 2,700 wooden poles in 2016.[18] Likewise, in 2018, Southeast Missouri invested \$1M to strengthen the electrical distribution system by replacing traditional wooden poles prone to tornado damage with composite poles, designed to withstand $300 \mathrm{mph}$ winds.[19] These examples suggest that, in areas prone to high winds, engineered composite poles may provide additional security during national disasters.

Again, possible changes in wind speed will affect the reliability performance of power pole infrastructure. Figure 14 shows the typical Australian power distribution pole layout. The pole diameter is in the range of 242-348 mm. [20] The design and dimension of these power poles can be collected for evaluating the possible impacts of the climate change on the power pole networks. 


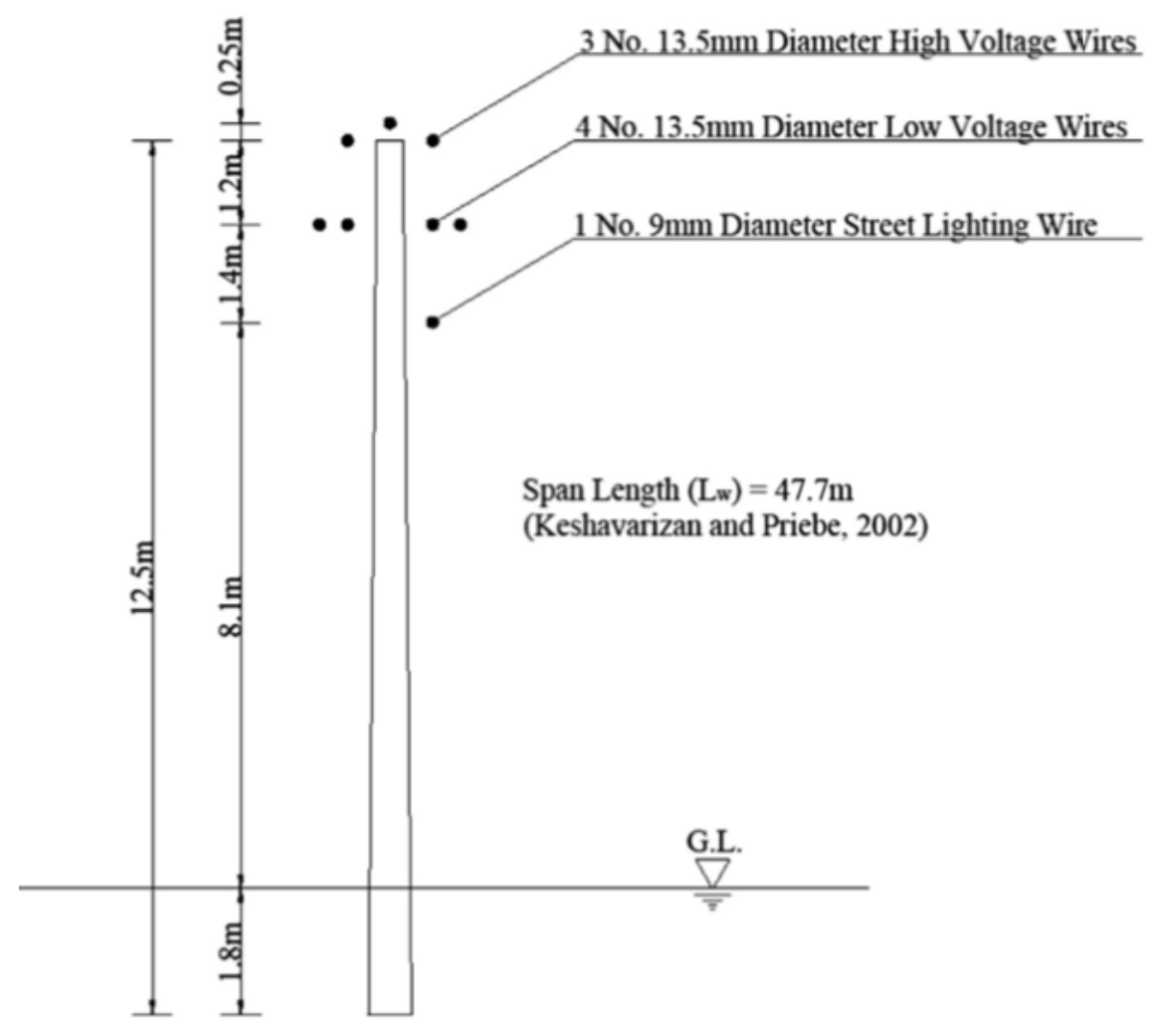

Figure 14: The power distribution pole layout. ${ }^{12}$

To protect the wooden utility poles from the natural environment, various preservatives have been developed. Preservatives used the wood pole treatment include creosote, chromated copper arsenate (CCA), and pentachlorophenol (penta).[21] The poles are typically dried prior to the treatment. To summarize, the comparison of penta-treated wood, concrete, and steel poles is shown in Table 3. The steel poles can rust with time, while concrete poles have the highest representative weight and total energy input among these poles. Concrete poles produced with high strength concrete are typically unlikely to be recycled due to low values of recovered products per cost of recovery. There seems to be no significant environmental emissions from the disposed concrete poles, though. ${ }^{13}$

Table 3: The comparison of penta-treated wood, concrete, and steel poles

\begin{tabular}{|c|c|c|c|}
\hline 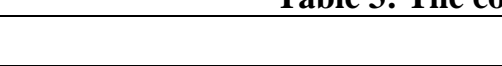 & Penta-treated wood & Concrete & Steel \\
\hline Length $(\mathrm{ft})$ & 45 & 45 & 45 \\
\hline Representative weight (lbs) & 1315 & 3793 & 631 \\
\hline Service life (year) & 60 & 60 & 60 \\
\hline $\begin{array}{l}\text { Total energy input } \\
\text { (MMBTU, cradle-to-grave) }\end{array}$ & 5.5 & 17 & 9.5 \\
\hline
\end{tabular}

There were approximately $120-200$ million treated timber poles in service in US. Even a small improvement in the network maintenance and design would result in a large amount of cost saving. The pole inspection frequency is typically $3-6$ years.[22] 


\section{OVERVIEW OF COMPOSITE POWER POLE PRODUCTION}

This section provides an overview of composites, manufacturing processes, the history of composite utility poles and current performance metrics in comparison to wooden utility poles.

\subsection{WHAT IS A COMPOSITE MATERIAL?}

A composite is a material made from two or more different materials that, when combined, are stronger than the individual materials by themselves (see Figure 15). There are a wide variety of composite materials such as carbon-fiber reinforced plastics, glass fiber reinforced aluminum, metal-matrix composites and ceramic-matrix composites. Reinforcements in a base material can include continuous fiber, chopped fiber, particles and any combination of these materials to give superior performance. As an example, ceramics such as concrete are typically strong in compression but weak in tension which can be overcome with the inclusion of steel reinforcements. Carbon fiber is very strong in tension but is weak in compression and bending. By weaving fibers together and binding with a resin (such as thermosets or thermoplastics) it is possible to create a very strong material. The combination of fibers and resins can lead to significant increases in strength without a penalty in weight which is why the aerospace and automotive industries, where fuel efficiency is directly proportional to weight, are increasing the usage of composites (see Figure 16).

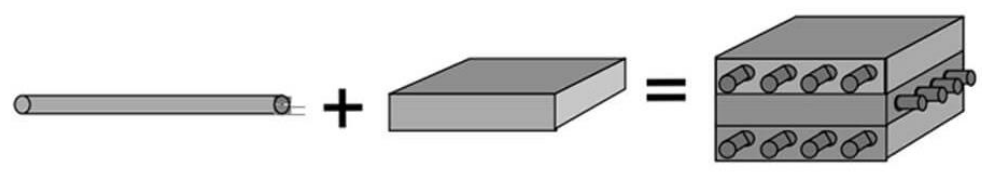

Fiber/Filament Reinforcement

Matrix

Composite

Figure 15: Fiber reinforced composite material

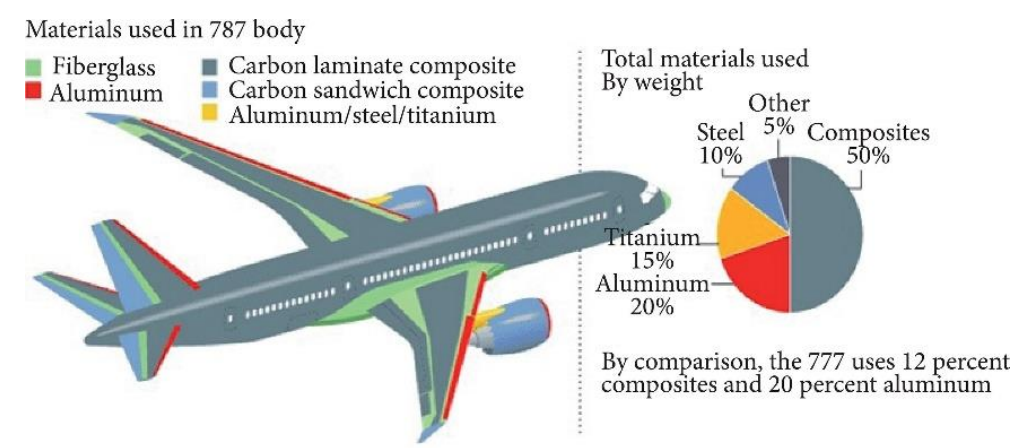

Figure 16: Material usage in Boeing 787

The increase in material complexity, which results in increased performance, typically increases the material cost. However, this can be a complex value proposition. First, while the material may cost more per lb to manufacture, the amount of material will likely be less. Even if the 
reduction in mass but increase in cost causes an overall increase in manufacturing cost, the reduction in mass can lead to a reduction in the lifetime cost. The aerospace and automotive industries have conducted this technoeconomic analysis on materials and have shown significant advantages in composites which is why there is an increasing adoption in these industries.

Power poles are stationary devices so reduction in weight will not directly result in reduction in energy costs over the lifetime of the pole. However, there may be other advantages that reduce the lifetime cost of composite poles. Unlike wooden poles, fiberglass reinforced plastic poles never rust (like steel poles) or splinter (like wooden poles) and are immune to insects and wildlife. While wooden poles degrade when exposed to the environment, composite poles are engineered to maintain their geometric tolerances and original strength throughout the life of the product.

\subsection{HOW ARE COMPOSITE POLES MANUFACTURED?}

Unlike wooden poles that are solid, composite poles are typically of a tubular construction. Tubes are typically much greater in strength and stiffness per unit mass compared to solid structures. The combination of tubular structure with increased material properties results in poles that are significantly lower in weight when compared to wooden poles which make transportation and installation significantly easier. There are two popular means of manufacturing composite tubes: filament winding and pultrusion. While modular poles are manufactured using a filament winding process, single-piece poles, as well as crossarms, are manufactured using the pultrusion process.[23] Details of both processes are given below.

\subsubsection{Filament Winding}

As described previously, fibers are extremely strong in tension but weak in compression and bending. A fiber composite structure needs to do two things during the manufacturing process. First, the process needs to provide fibers in the directions of the anticipated load (forces) exerted on body during its use. This can be in multiple directions. Second, there must be a matrix (resin) that holds the fibers in place. Filament winding is mainly used for manufacturing open or closed cylindrical structures. The process involves winding fibers under tension over a rotating mandrel. The mandrel rotates while the fiber traverses horizontally back and forth over the mandrel laying down fibers in the desired pattern and angle (see Figure 17). Once the mandrel is completely covered to the desired thickness, the resin is cured, and mandrel removed leaving a hollow fiber composite structure. The advantage to this process is fine control over the fiber placement as well as the ability to manufacture complex tubular structures. The disadvantage is the batch process which does not lend itself easily to high-rate production. 


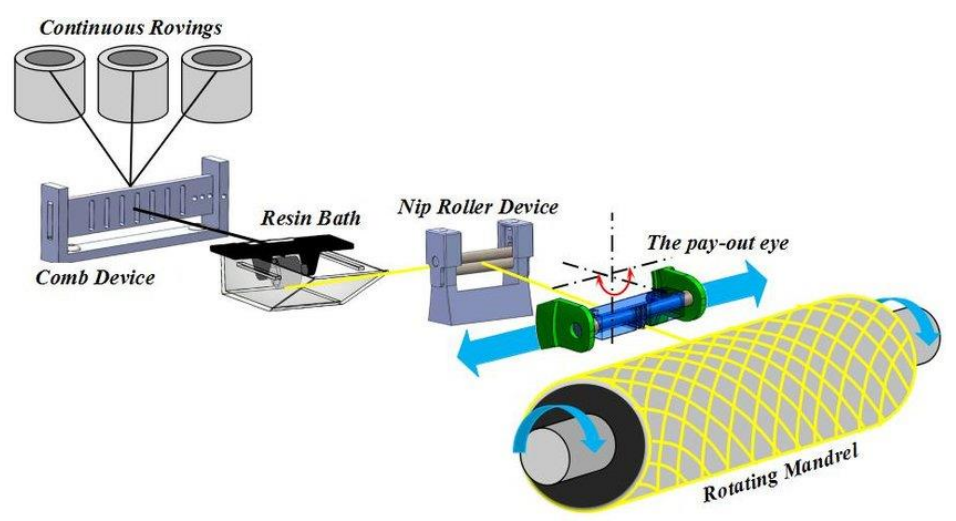

Figure 17: Filament winding

\subsubsection{Pultrusion}

In a similar manner, pultrusion (see Figure 18) is based on manufacturing tubular fiber composite structures. Unlike filament winding where the fibers are pulled onto a rotating mandrel, pultrusion is based on pulling and translating the fibers over a hot die much like an inchworm. The fibers, as well as a multi-directional matt, are pulled into a set of heated dies to control the shape. The two dies translate back and forth, sequentially grasping and releasing the fibers, controlling the shape and extruding into a continuous tubular structure where the dies control the shape of the tubular structure. Unlike fiber winding which is a batch process, pultrusion is a continuous process where the fiber reinforced tubular structure continuously grows out of the system. A chop saw controls the length of the tube by timing the cutting with the extrusion rate. The advantage of pultrusion is that it is a continuous process with extremely high production rates. The disadvantage is that it can only create tubes with a constant cross section. It is not currently possible to produce tapered structures or tubes with varying diameters as can be done in fiber winding.

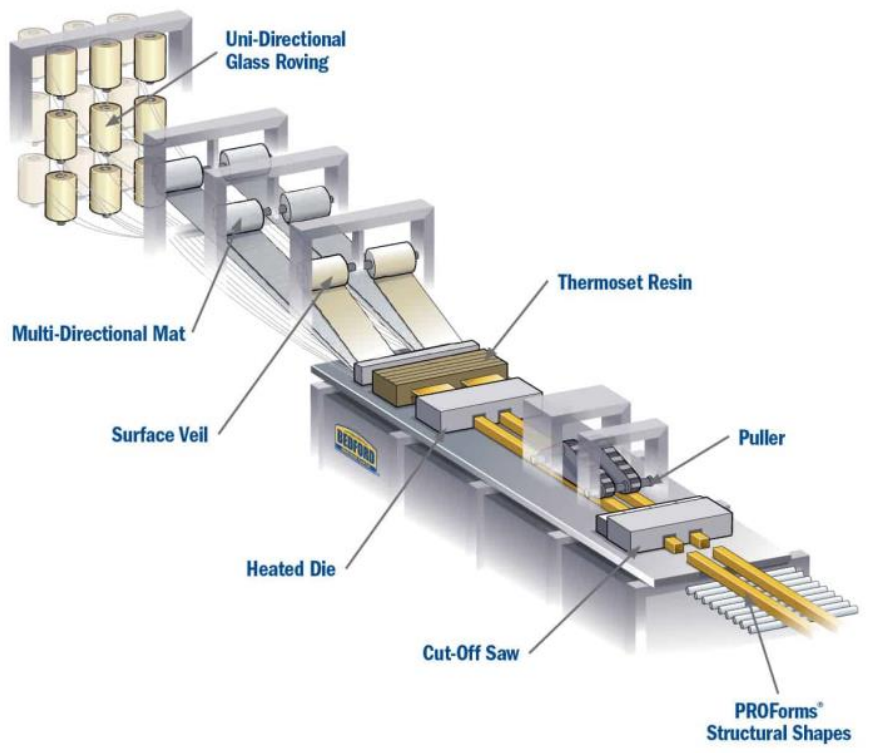

Figure 18: Pultrusion process 


\subsection{HISTORY OF COMPOSITE UTILITY POLES}

The first fiber-reinforced composite (FRC) utility poles were manufactured and installed on the island of Maui in the early 1960's replacing wood and steel poles that suffered degradation (wood) and corrosion (steel) caused by the warm, moist, salty air. The first fiber-reinforced poles lasted approximately 45 years. The primary reason for replacement was due to degradation from UV that resulted in fraying of the surface fibers. The first composite distribution poles were installed in 1993 and the first transmission pole (70 ft tall) in 1996. Latest innovations include large iso-truss transmission structures using lattice framework construction.

As an example, Strongwell has manufactured fiberglass power transmission poles that are $30 \%$ the weight of wood and 15\% of or less of concrete (see Figure 19). The poles are manufactured via a pultrusion process (see Figure 18) using various glass fiber reinforcements that include multi-directional glass fabric as well as wound fibers. An internal foam core combined with the high tensile strength of the composite provide the poles excellent performance when subjected to vertical and lateral loads due to standard service as well as environmental conditions such as high wind loads due to severe weather.

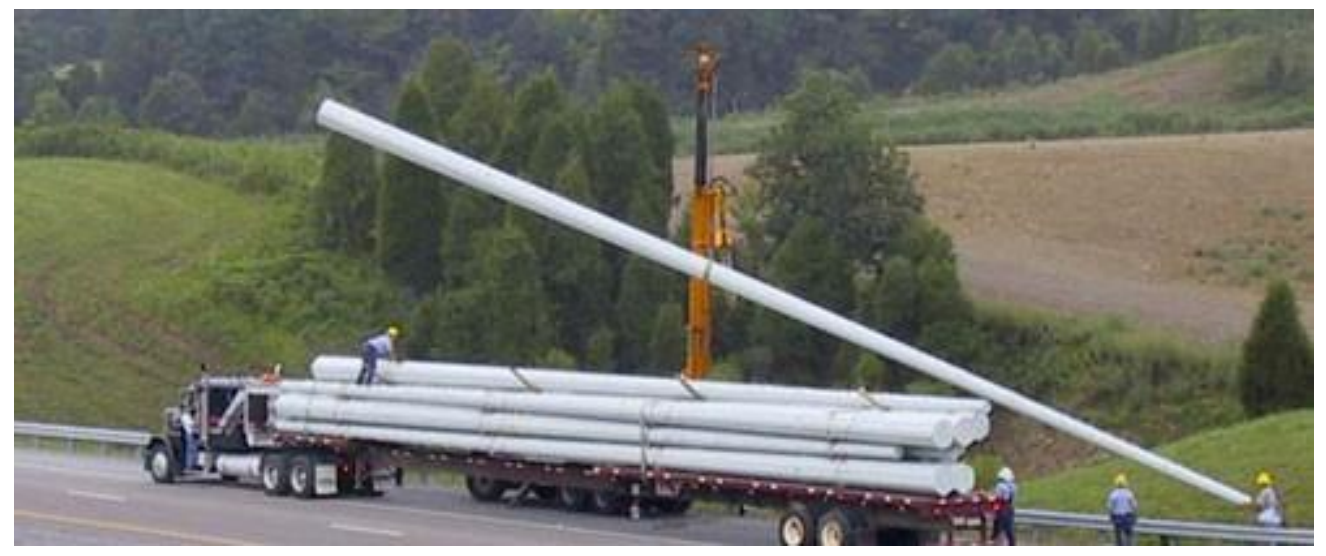

Figure 19: Fiberglass composite utility poles 


\section{OVERVEIW OF CURRENT COMPOSITE POWER POLE PERFORMANCE}

In general, fiber-reinforced composite poles are lightweight, strong and have low conductivity properties. They resist rot and corrosion, don't require chemical preservatives, newer resins are resistant to UV degradation, have low water absorption and are immune to insects and woodpeckers. Unlike wooden poles, composites do not lose strength as they age, have excellent electrical properties and are able to withstand high wind loads and impacts. Although the material is not fireproof, they are fire resistant. With one coat of fire retardant, they become attractive to service utilities containing brushy terrain, forests, or combination of both. On the other hand, composite poles are not widely used for high voltage applications (above 230kV), possibly due to the greater amount of deflection under load compared to steel and concrete, and also due to the lack of knowledge of how the material performs in a high electric field environment. Table 4 provides a summary of material properties of poles based on the manufactured material.

Table 4: Material property comparison

\begin{tabular}{|l|l|l|l|l|}
\hline Property & Steel & Concrete & Wood & Composite \\
\hline Density (pcf1) & 490 & 150 & 60 & 45 \\
\hline $\begin{array}{l}\text { Mod. of } \\
\text { Elasticity (ksi2) }\end{array}$ & 29,000 & 5000 to 6000 & 1800 to 1900 & $\begin{array}{l}20,000 \text { to } 22,000 \\
* * *\end{array}$ \\
\hline $\begin{array}{l}\text { Expected } \\
\text { Service Life } \\
\text { (years) }\end{array}$ & $60^{*}$ & 50 & $45^{* *}$ & 70 to 100 \\
\hline $\begin{array}{l}\text { Coefficient of } \\
\text { Thermal } \\
\begin{array}{l}\text { Conductivity } \\
(\text { Btu/hr/ft/in/F) }\end{array}\end{array}$ & 25 to 40 & 10 & 0.8 to 1.2 & 5 \\
\hline
\end{tabular}

* galvanized

$* *$ treated

$* * *$ depending upon manufacturing

For the engineered materials (concrete, steel and composites, since the poles are hollow, it is possible to emplace wireless, cellular, satellite and radio antennas, devices and dishes. Being hollow and non-metallic, wiring can be located inside the pole including copper grounding wire prone to theft.

As mentioned earlier, composite poles have been successfully applied in distribution and transmission grids since 1960's. Composite utility poles have some advantages over traditional poles: ultra-violet (UV) protection, longer service life, less inspection frequency, and less maintenance. These composite utility poles consist of glass fibers and a polymer matrix system.

$1 \mathrm{pcf}$ - pound per cubic foot density

$2 \mathrm{ksi}$ - thousand pounds per square inch pressure 
The glass fiber is continuous roving E-glass. The polymer system contains both UV stable and aromatic aliphatic polyurethane resin. Table 5 shows the laminate flexural strength retention of composite utility poles for different locations and service periods.[24]

Table 5: The laminate flexural strength retention of composite utility poles made by RS Technologies Inc. for different locations and service periods. ${ }^{16}$

\begin{tabular}{|l|l|l|l|l|l|}
\hline Location & $\begin{array}{l}10 \text { years } \\
(\%)\end{array}$ & $\begin{array}{l}20 \text { years } \\
(\%)\end{array}$ & 40 years $(\%)$ & 60 years $(\%)$ & 80 years $(\%)$ \\
\hline Calgary, Alberta & 92 & 87 & 82 & 80 & 79 \\
\hline Tucson, Arizona & 88 & 83 & 80 & 76 & 74 \\
\hline Toronto, Ontario & 88 & 83 & 79 & 77 & 75 \\
\hline Miami, Florida & 84 & 79 & 76 & 72 & 70 \\
\hline
\end{tabular}

Non-UV stable composites are susceptible to degradation from exposure to UV light.[24] Other weathering factors such as high temperature and moisture can influence the power poles. The possible damage caused by weathering includes color fading, loss of gloss, cracking, yellowing, embrittlement, loss of mechanical strength, chalking, etc. In addition, such damage may result in glass exposure.[24]

Some manufacturers have used the method of applying paint or veil cloth coating on the outer surface to add a physical barrier between the weathering factors and the composite. ${ }^{16}$ However, coating can be easily scratched and damaged, reducing its protective benefits. Different composite pole testing approaches are shown below.[24]

(1) It is significant to test the weatherability, long term durability, and UV light stability of the composite poles. Two common methods are xenon arc light stability and fluorescent UVA accelerated weathering tests. These tests can provide relatively reproducible and fast results. (2) Mechanical tests: flexural strength, flexural modulus, and inter-laminar shear strength.

(3) Electrical testing: dielectric strength and flashover. The moisture influences composite pole, especially in standing water. When the poles are installed in the field, the laminate in the base module is exposed to moisture from the surrounding soil.

(4) Lightning strike: Composite utility poles made by glass fibers and polyurethane matrix has a high insulation because both components are non-conductive.

Beyond the above testing, the inspection and maintenance of power poles are shown below.[24]

(1) Excessive leaning

(2) Erosion

(3) Scratch, impact damage

(4) Burning due to lightning or fire

(5) Hole

(6) Hardware (bolt, cross arm, cross brace, mounting bracket, pole band, etc.)

A properly maintained wooden pole can last 35 years or longer.[25] However, the service life of a wooden pole can be negatively affected by natural enemies such as termite, woodpecker, fire, rot, high wind, and excess loading. Because of this situation, concrete and steel poles have been utilized. To improve the performance of the utility poles further, composites have been utilized. The composite poles were first installed in Hawaii during the early 1950s. The composite poles 
can last up to 80 years. The composite poles are easier to install and handle (shown in Figure 20) due to their reduced weight, compared to heavy wood poles. Helicopters are commonly used to set wood poles. The composite exhibits a non-conductive nature, making it safer for the utility crews and public, compared to wooden, concrete or steel. The composite pole does not rust, unlike steel poles.[25]

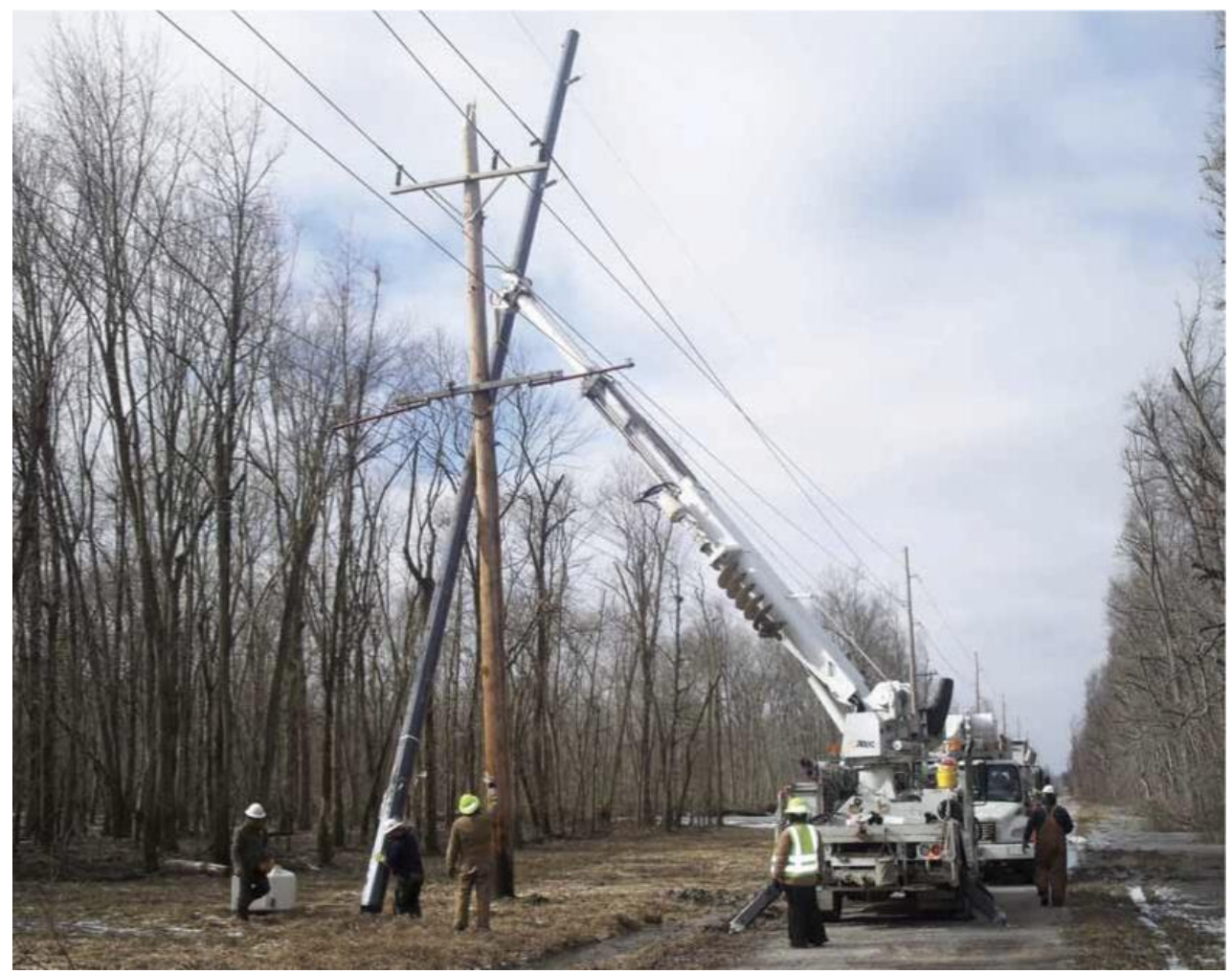

Figure 20: A new composite pole was set in this distribution line. Due to its lightness, the composite pole is easier to install than the wooden or other heavier poles.[25] 


\section{ASSESSMENT OF KNOWLEDGE GAPS AND FUTURE OPPORTUNITIES}

The importance of the standard utility pole cannot be overstated. There are approximately 150 million utility poles in service in the US that are responsible for the transmission approximately 38 Quads of electricity to 330 million people. These poles are designed to last many decades and be exposed to extreme weather including large swings in temperatures, humidity, wind, ice as well as insects and animals. During severe climate events (hurricanes, ice storms, fires) failure of power poles leads to loss of electrical power when it is needed the most. As described earlier, there are emerging material options that can be optimized for different environments. Recent experience has shown that concrete poles have greater ability to survive wildfires, whereas composite poles have shown the ability to sustain high wind loading during hurricanes.

The great earthquake in Japan in 1995 damaged about 11300 power poles.[26] If the concrete portion of the concrete pole is destroyed, the pole starts to incline, which can cause the pole to collapse. Collapse of poles in big cities causes not only long-term power outages, but also hazards to earthquake refugees and rescue activities. This event indicates the necessity to study the dynamic behavior of power poles caused by the movement of the ground. In this published study, a real power pole was set up on a vibration testing machine, shown in Figure 21. The base was mounted by an iron flange that was used in fasting the pole to the table of the machine. It is found from the experiment that the oscillation of a power pole is not restricted within one-dimensional space, but moving within a two-dimensional horizontal space.[26] For the composite power poles that will be developed, the knowledge on their dynamic behavior will be helpful to assess the pole performance. 


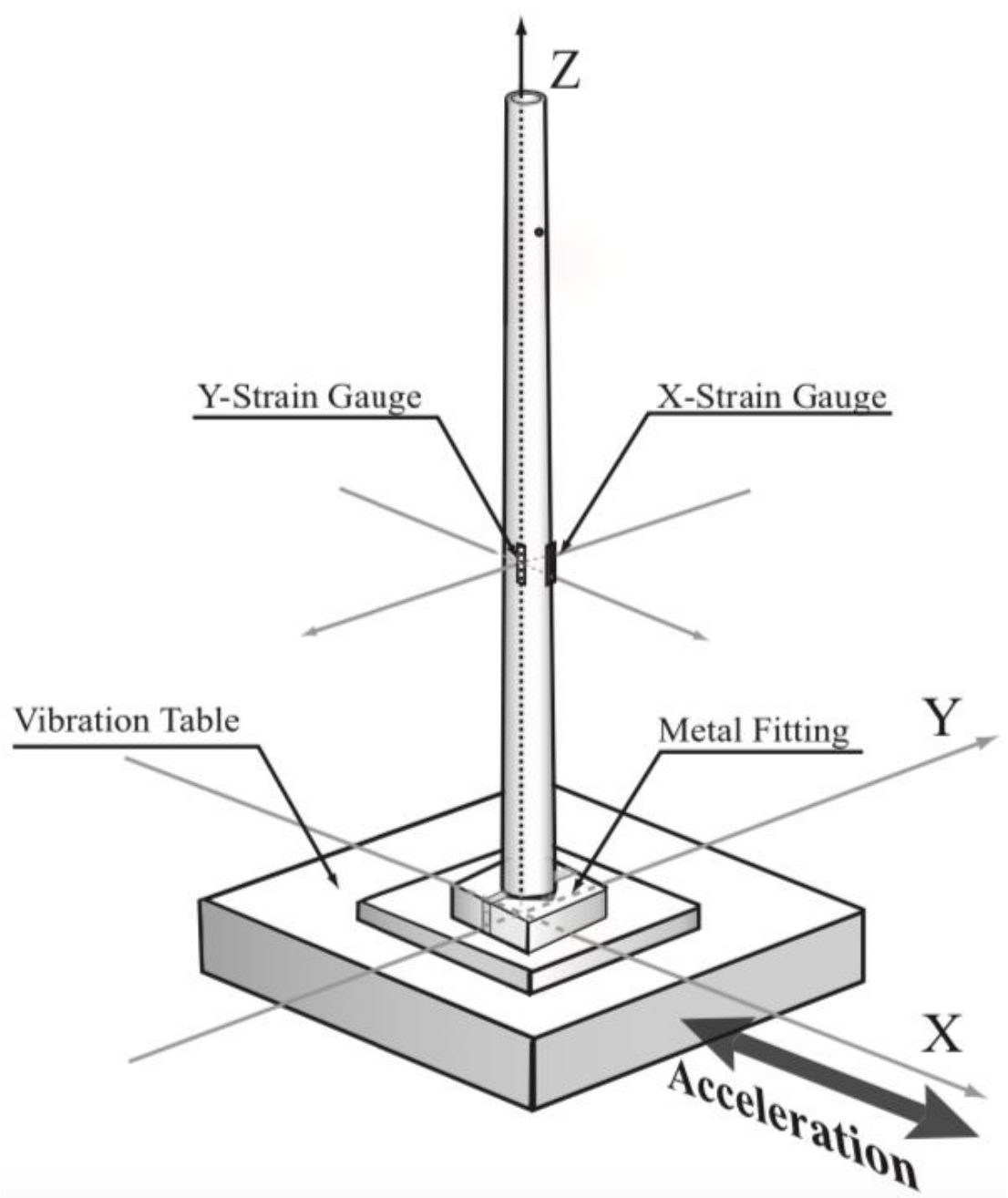

Figure 21: Vibration testing machine.[26] 
The pole network is vulnerable to increased wind speeds from climate change.[27] Changes in temperature and rainfall can accelerate timber decay, influencing residual capacity of timber poles. In a different study, the authors utilized a stochastic simulation method to examine climate change impacts and possible adaptation strategies such as installation of larger poles, changes to pole replacement criteria, and more frequent inspections. The mean inspection cost per pole in Australia is approximately $\$ 23-104$. [27] It will be critical to investigate the effect of climate change such as wind speed on the performance of composite power poles.

The knowledge on the investigation of composite power poles will be needed to evaluate their performance. There are some investigation methods including moisture content verification, pole surface conductivity testing, leakage current test under wet and dry conditions, and pole impedance study. ${ }^{5}$

Poles with conductors situated over crossarms typically result in high mortality.[28] The estimated mean annual death rate is 4.5 birds per 100 poles. It is critical to design safe and new poles to prevent electrocution. The bird habitat type is helpful for providing a management tool to optimize an investment for protecting birds.[28]

The local prey abundance may affect the frequency of birds of prey perching on poles. [29] Main mitigation methods for reducing risks of electrocution include isolation, insulation, and perch discourage/deflector (reducing the likelihood of bird perching in position on poles). Isolation and insulation are relatively more expensive than perch discourage at dangerous poles. Figure 22 shows the pole crossarm with zero perch deflector spike, two perch deflector spikes, and four perch deflector spikes. Results exhibit that perch deflectors can reduce the electrocution frequency on line poles.[29]
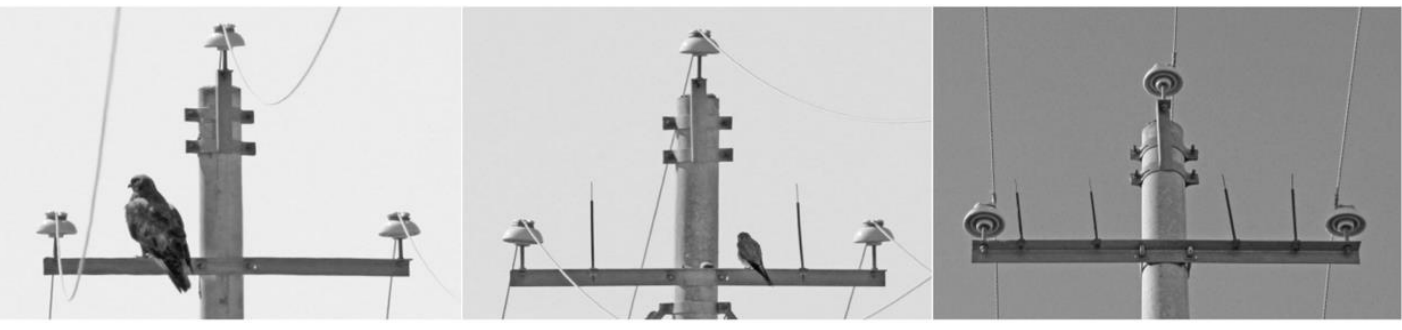

Figure 22: Pole crossarm with zero perch deflector spike (left), two perch deflector spikes (center), and four perch deflector spikes (right). Experimental results show that the perch deflectors can reduce the electrocution frequency on line poles.[29]

\subsection{KNOWLEDGE GAPS}

There are national standards for loading conditions but there is a knowledge gap in a clear, unbiased comparison between material options. Some of the potential barriers to increased usage of composite poles are unknown aging or degradation mechanisms, lack of product standardization, lack of guidance for inspection/ assessment practices, and lack of field experience with the material, particularly at voltages of $230 \mathrm{kV}$ and above, unlike more common steel or concrete poles.[23] Extensive testing is required to understand the material properties and how they change over time, the modes of failure, and the environmental factors that start the degradation process, and for the adoption of this technology. However, due to the relatively short history of the use of composite poles, only a limited data is currently available.[23]

To begin, there needs to be a design of experiments that can encapsulate the full range of 
environmental conditions that can baseline utility pole performance as a function of material and design. This needs to be coupled with a technoeconomic analysis to understand the long-term costs associated with insertion of new technologies. Once the experimental design is standardized, new designs and materials can be developed to help reduce cost and increase reliability.

\subsection{FUTURE OPPORTUNITIES}

Reducing the cost of composite power poles plays a significant role in their applications. For example, the used composites can be recycled for producing power poles. Innovative and costeffective manufacturing methods need to be developed. Poles exhibit new properties derived from the appropriate distributions such as pole bending strength, pole diameter, and sapwood depth. $\left[{ }^{30}\right]^{27}$ Preliminary result indicates that the typical cost of pole condemning and subsequent replacement is approximately $\$ 7500$. The typical cost associated with the pole wind failure is approximately $\$ 60000$.[30] In addition, the cost and energy analysis on the composite power pole production and maintenance can be calculated to predict their applications in appropriate areas.

We outline two near term opportunities for composite pole research. The first opportunity is related to on-site production of power poles during a recovery period from a natural disaster such as a hurricane. The second opportunity is the use of recycled material for production of low cost yet durable composite poles. Hybrid approaches combining multiple materials, such as composites and concrete, as well as recycled materials may also offer additional benefits compared to conventional approaches.

4.2.1.RECYCLED BIOMATERIALS FOR SHORT TERM DISASTER RELIEF

As described in the section on requirements, during a natural disaster, reduced grades of poles are viable for short term use. One option is to explore on-site manufacturing of power poles using biomaterials from debris. ORNL conducted a screening of 3D printed power poles.

\subsubsection{USE OF WASTE STREAMS FOR LOW-COST COMPOSITE POLES}

There are a number of current waste streams (wind turbine blades, tires) that have the potential to simultaneously reduce material cost and eliminate environmental disposal by combining into a next generation of low-cost composite power poles. While composite poles have shown improved performance, the primary barrier to wide scale adoption is cost. The use of recycled material to augment current material costs may reduce the net cost significantly enabling a more economical and environmentally friendly manufacturing strategy for highly durable, long-life low-cost utility poles. There are approximately 300 million tires disposed of every year in the US. This is almost one tire per person per year. Some of the challenges with tires (durability) could be advantageous for composite power poles. Likewise, there are anticipated to be more than 720,000 tons of blade material to dispose of over the next 20 years. There are tremendous opportunities in the circular economy where we can increase the value of products through recycling old waste to new products (see Figure 50 and Figure 51). 


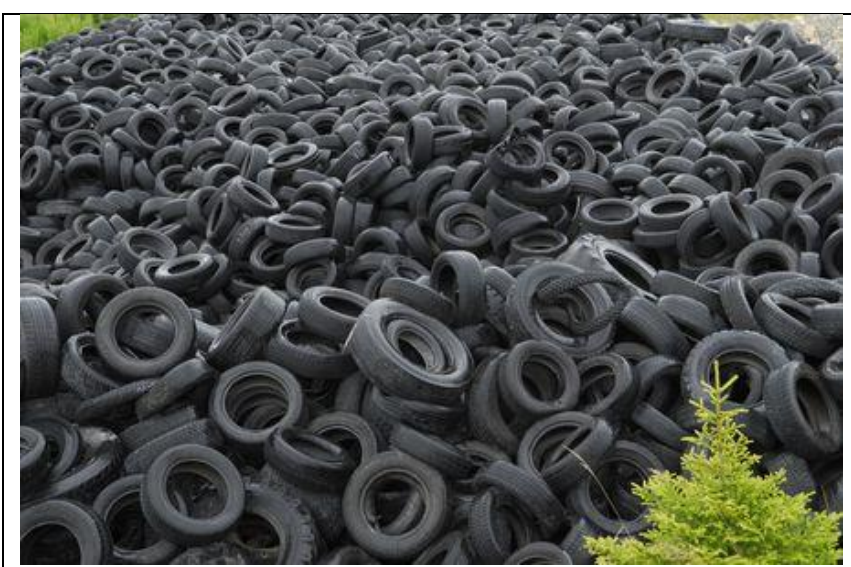

Figure 50: Waste tires

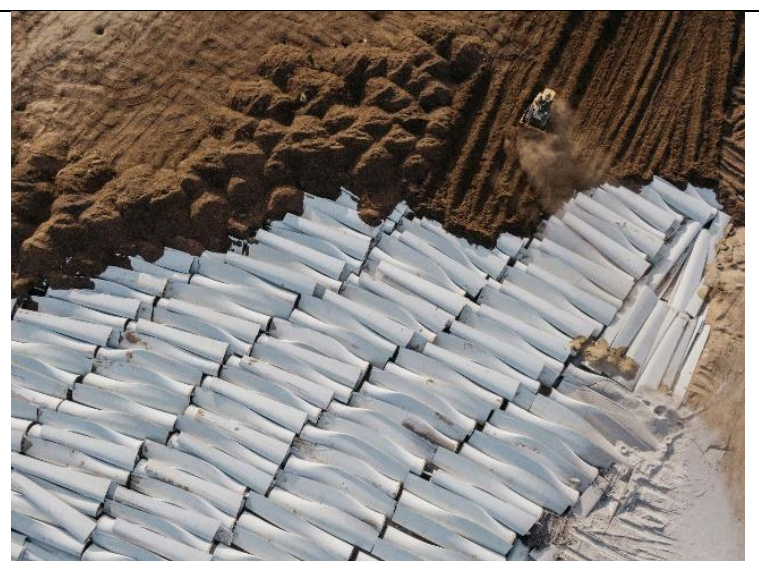

Figure 51: Waste wind turbine blades 


\section{CONCLUSIONS AND RECOMMENDATIONS}

The US market for distribution poles is approximately \$9B/yr. It is estimated that about 3.6 million distribution poles (mostly wood) have to be replaced each year. In addition, about 2.4 million new poles are added annually. The current US capacity for manufacturing composite poles is approximately 20,000 poles/year. Despite the benefits and advantages, utilities have been reluctant to deploy composites. Composite poles are typically more expensive up front, nearly twice the cost of wooden poles for distribution applications. However, the price difference diminishes significantly with larger transmission sized poles. Because many utilities are focused on low upfront price and not total life cycle cost, composite poles are not deployed as much as they could be. If a cost-benefit analysis is performed, a more complete picture of the total cost of asset ownership may become apparent. Composites have a longer life span, installation costs are lower because installation is quicker, and only light duty equipment is required. Maintenance costs are likewise lower.[31] There are near term opportunities to baseline material characteristics for utility poles and explore new materials and manufacturing processes to reduce composite material costs and increase utility pole durability and life. 


\section{REFERENCES:}

[1] https://pluggedin.psegliny.com/2016/08/19/look-up/

[2] http://osmoseutilities.360psg.com/documents/Pole\%20Loading\%20101.pdf

[3] https://www.howmuchisit.org/telephone-poles-cost

[4] M. Horwood, Termite and power pole evaluation research project, (2007).

[5] P.J. Sokolowski, A. Dwivedi, S. Pathak, F. Buratto, X. Yu, Investigating the impedance of a wooden power pole after a pole fire, 2008 Australasian Universities Power Engineering

[6] https://www.steel.org/steel-markets/steel-utility-poles/

[7] https://www.scgrp.com/StresscreteGroup/media/images/products/StressCrete-Spun-Concrete-UtilityPoles-Brochure.pdf

[8] https://polesaver.com/blog/utility-pole-materials-review-which-is-best/

[9] Pole Service Life - An analysis of Country Energy Data (Australia), Nathan Spenser Koppers Wood Products, Sydney, Australia.

[10] https://www.preventionweb.net/publications/view/64881

[11] https://electricenergyonline.com/energy/magazine/1148/article/Weathering-the-Weather-The-

Benefits-of-Composite-Utility-Poles-in-Storm-Zones.htm

[12] https://spectrum.ieee.org/energy/policy/rebuilding-puerto-ricos-power-grid-the-inside-story

[13] https://www.democratandchronicle.com/story/news/2017/08/18/windstorm-damage/537351001/

[14] http://compositesmanufacturingmagazine.com/2018/05/rochester-to-spend-1-25-million-compositeutility-poles/

[15] http://compositesmanufacturingmagazine.com/2018/09/rolling-with-the-punches/

[16] https://electricenergyonline.com/energy/magazine/1148/article/Weathering-the-Weather-The-

Benefits-of-Composite-Utility-Poles-in-Storm-Zones.htm

[17] https://www.bostonglobe.com/news/world/2014/09/15/hurricane-odile-slams-mexico-baja-

california/7e3acNIMtyZWhXQUxqWHSN/story.html

[18] https://electricenergyonline.com/energy/magazine/1148/article/Weathering-the-Weather-The-

Benefits-of-Composite-Utility-Poles-in-Storm-Zones.htm

[19] https://www.kfvs12.com/story/38270627/new-composite-utility-poles-in-southeast-mo-expected-towithstand-strong-wind-ef5-tornado/

[20] P.C. Ryan, M.G. Stewart, N. Spencer, Y. Li, Probabilistic analysis of climate change impacts on timber power pole networks, International Journal of Electrical Power \& Energy Systems, 78 (2016) 513 523

[21] C.A. Bolin, S.T. Smith, Life cycle assessment of pentachlorophenol-treated wooden utility poles with comparisons to steel and concrete utility poles, Renew Sust Energ Rev, 15 (2011) 2475-2486.

[22] P.C. Ryan, M.G. Stewart, N. Spencer, Y. Li, Reliability assessment of power pole infrastructure incorporating deterioration and network maintenance, Reliability Engineering \& System Safety, 132 (2014) 261-273.

[23] EPRI, Management of composite structures, https://www.epri.com/research/products/000000003002020576

[24] M. Zhang, G. Fecht, RS composite utility pole inspection and maintenance guide, (2012) 1-16.

[25] M. Skea, Composites manufacturing: Composites solutions to utility line challenges, American Composites Manufacturers Association, Tom Dobbins, 2011.

[26] S. Togawa, N. Ichikawa, M. Kobayashi, Improvement of seismic-proof-ability concerned with the power pole system, 2005/2006 IEEE/PES Transmission and Distribution Conference and Exhibition, 2006.

[27] P.C. Ryan, M.G. Stewart, Cost-benefit analysis of climate change adaptation for power pole networks, 
Climatic Change, 143 (2017) 519-533.

[28] G. Janss, M. Ferrer, Avian electrocution mortality in relation to pole design and adjacent habitat in Spain, Bird Conservation International, 11 (2001) 3-12.

[29] A. Dixon, M.L. Rahman, B. Galtbalt, A. Gunga, B. Sugarsaikhan, N. Batbayar, Avian electrocution rates associated with density of active small mammal holes and power-pole mitigation: Implications for the conservation of Threatened raptors in Mongolia, Journal for Nature Conservation, 36 (2017) 14-19.

[30] P.C. Ryan, M.G. Stewart, N. Spencer, Cost-effective design and maintenance of timber power distribution poles in a changing climate, 12th International Conference on Applications of Statistics and Probability in Civil Engineering, 2015.

[31] https://energycentral.com/c/tr/composite-transmission-and-distribution-poles-new-trend 